\title{
Synthesis of Barringtogenol C Derivatives and Their Cytotoxic Activities
}

\author{
Barringtogenol C Türevlerinin Sentezi ve Sitotoksik \\ Aktivitelerinin İncelenmesi
}

\author{
Research Article
}

Derya Gülcemal* and Ayşe Nalbantsoy

Ege University, Department of Chemistry, Izmir, Turkey.

\section{A B S TR AC T}

\begin{abstract}
A series of barringtogenol $C$ (1) derivatives (2a-c, 3a-c, 4a-c, 5a-d, 6a,b and 7 were synthesized and screened A in cytotoxicity assay against various cancer cell lines (HeLa, A549, U87MG, CaCo-2 and MCF-7) together with the normal cell line Vero. Many of the compounds screened have been found to have significantly improved anti-cancer potency in comparison with doxorubicin or barringtogenol C (1). Compound 3 a was found to be 26-fold more active than doxorubicin. It was also not toxic to the non-tumoral Vero cells tested under in vitro conditions. In conclusion, compound 3a tested strong cytotoxicity against cancer cells, which could be a promising anti-cancer lead compound for further studies.
\end{abstract}

\section{Key Words}

Styrax officinalis, Triterpene, Barringtogenol C, Cytotoxic activity.

\section{öz}

ir dizi barringtogenol $C$ (1) türevleri (2a-c, 3a-c, 4a-c, 5a-d, 6a,b and 7) sentezlenmiş ve Vero normal hücre hattı ile birlikte çeşitli kanser hücre hatları ile (HeLa, A549, U87MG, CaCo-2 and MCF-7) çalışılmıştır. Doksorubisin ve barringtogenol C ile kıyaslandığında bileşiklerin çoğunun antikanser potensiyelinde anlamlı bir gelişme olduğu görülmüştür. Bileşik 3a nın doksorubisinden 26 kat daha aktif olduğu bulunmuştur. Ayrıca in vitro koşullar altında test edilen Vero normal hücre hattında toksik değildir. Sonuç olarak bileşik 3a ileri çalışmalar için umut verici antikanser öncü bileşik olabilecek, kanser hücre hatlarına karşı güçlü sitotoksik aktiviteye sahiptir.

\section{Anahtar Kelimeler}

Styrax officinalis, Triterpen, Barringtogenol C, Sitotoksik aktivite.

Article History: Received: May 22, 2017; Revised: Aug 2, 2017; Accepted: Sep 29, 2017; Available Online: Dec 25, 2017.

DOI: 10.15671/HJBC.2018.189

Correspondence to: D. Gülcemal; Ege University, Department of Chemistry, İzmir, Turkey. 


\section{INTRODUCTION}

S aponins are a vast class of natural products whose structural diversity includes a wide array of functional groups. Many compounds of this group are reported to have anti-inflammatory [1], anti-viral [2], anti-tumor [3,4], hepatoprotective [5,6], anti-hyperlipidemic $[5,7]$, anti-obesity [8,9], hypoglycemic [10-12], antihypertensive [13], immunomodulatory [14-16], neuroprotective [17,18], anti-inflammatory $[15,19,20]$, anti-tumor $[3,21,22]$, anti-oxidant [18], wound healing $[23,24]$ and anti-carcinogenic [20,25-27], anti-atherosclerositic [28], cytotoxic and apoptotic activities [16,22,29$32]$ and chemopreventive $[20,33,34]$ effect.

Recently, saponins have been recognized as potent tumor inhibitors, and they have suddenly become one of the primary targets for new pharmacologically active anti-tumor molecules. Selective cytotoxic activity of oleanolic acid isolated from rhizomes of Astilbe chinensis towards the HeLa cancer cell line with a value of $\mathrm{IC}_{50}=6.49 \mu \mathrm{g} /$ $\mathrm{mL}$ was reported by H.X. Sun $[35,36]$. Derivatives of oleanolic acid, that are formally derived from 2-cyano-3,12-dioxooleana-1,9(11)-dien-28-oic acid (CDDO), showed a range of interesting effects. In vitro studies have shown that CDDO induces cell differentiation, growth inhibition, and apoptosis in human leukemia [37,38], osteosarcoma [39] and breast cancer [40] cell lines. Further studies exhibited that the genes (IAP-2, BCL-2, C-MYC, VEGF, MMP-9) related with NF- $\kappa B$ (nuclear factor kappa B) were suppressed by CDDO. Another study showed that the cytotoxic action of CDDO and its derivatives in glioblastoma and neuroblastoma was through inhibition of $\mathrm{NF}^{-} \mathrm{KB}$ [41]. Two of synthetic oleanane derivatives, 2-cyano-3,12dioxooleana-1,9(11)-dien28-oic acid (CDDO) and its methyl ester (CDDO-Me) are under evaluation in phase I clinical trials to test for their anti-cancer properties $[19,27,35,42]$.

Barringtogenol C (olean-12-ene$3 \beta, 16 \alpha, 21 \beta, 22 \alpha, 28 \beta$-pentol) (1), an oleanane-type triterpenoid is a prevalent pentacyclic triterpenoid which has been found in various plants in both aglycone and glycoside forms including Barringtonia racemose [43], Aesculus pavia [44], Eryngium yuccifolium [45], Careya arborea [46], Styrax japonica [47], Styrax officinalis $[48,49]$,
Aesculus hippocastanum [50] and Antonia ovata [51]. Several barringtogenol $C$ type triterpenoids have shown promising activities against A549 (human non-small cell lung tumor) [52], PC-3 (human prostate) [52], HL-60 (Human promyelocytic leukemia cells) [52], PANC-1 (Human pancreatic carcinoma, epithelial-like cell line) [52], MRC-5 (human fetal lung fibroblast) [52], J-774 (murine monocyte/macrophage) [44], WEHI-164 (murine fibrosarcoma) [44] and KB (human mouth epidermal carcinoma) [51] cell lines.

In the present study, we report the synthesis, characterization, and cytotoxicity of a new series of Barringtogenol C (1) derivatives against the cell lines of Human lung adenocarcinoma epithelial (A549), human cervix adenocarcinoma (HeLa), human colorectal adenocarcinoma (CaCo-2), human glioblastoma-astrocytoma (U-87 MG) and human breast adenocarcinoma (MCF-7).

\section{RESULTS and DISCUSSION}

\section{Chemistry}

The synthetic pathway in the present work is outlined in Scheme 1. Barringtogenol $\mathrm{C}$ isolated from the pericarps of fruits of Styrax officinalis $L$. was used as the key starting material.

The reaction of 1 with 2,2-dimethoxypropane (DMP) and $p$-toluenesulfonic acid $(p T s O H)$ in DMF at room temperature gave the compounds $\mathbf{2 a - c}$ after 12 h. Compounds $\mathbf{3 a - c}, \mathbf{4 a - c}, \mathbf{5 a - d}, \mathbf{6 a}, \mathbf{b}$ and $\mathbf{7}$ were synthesized by the reaction of 1 with anhydride in the presence of 4-dimethylaminopyridine (DMAP) in dry pyridine at reflux temperature for $4 \mathrm{~h}$.

\section{Cytotoxicty Evaluation}

The target compounds $\mathbf{2 a - c}, \mathbf{3 a - c}, \mathbf{4 a - c}, \mathbf{5 a - d}$, $\mathbf{6} \mathbf{a}, \mathbf{b}$ and $\mathbf{7}$ were subjected to evaluation for their cytotoxic activity against CaCo-2, HeLa, MCF7, A549, U87MG cancer cells and the normal cell Vero by modified MTT assay $[53,54]$. Doxorubicin was used as a control drug. The estimated IC ${ }_{50}$ values are listed in Table 1.

Among all, the compounds $2 b, 3 b$ and $3 c$ showed promising cytotoxic activity against five cancer cell lines, whereas compound $2 \mathrm{a}$ exhibited 

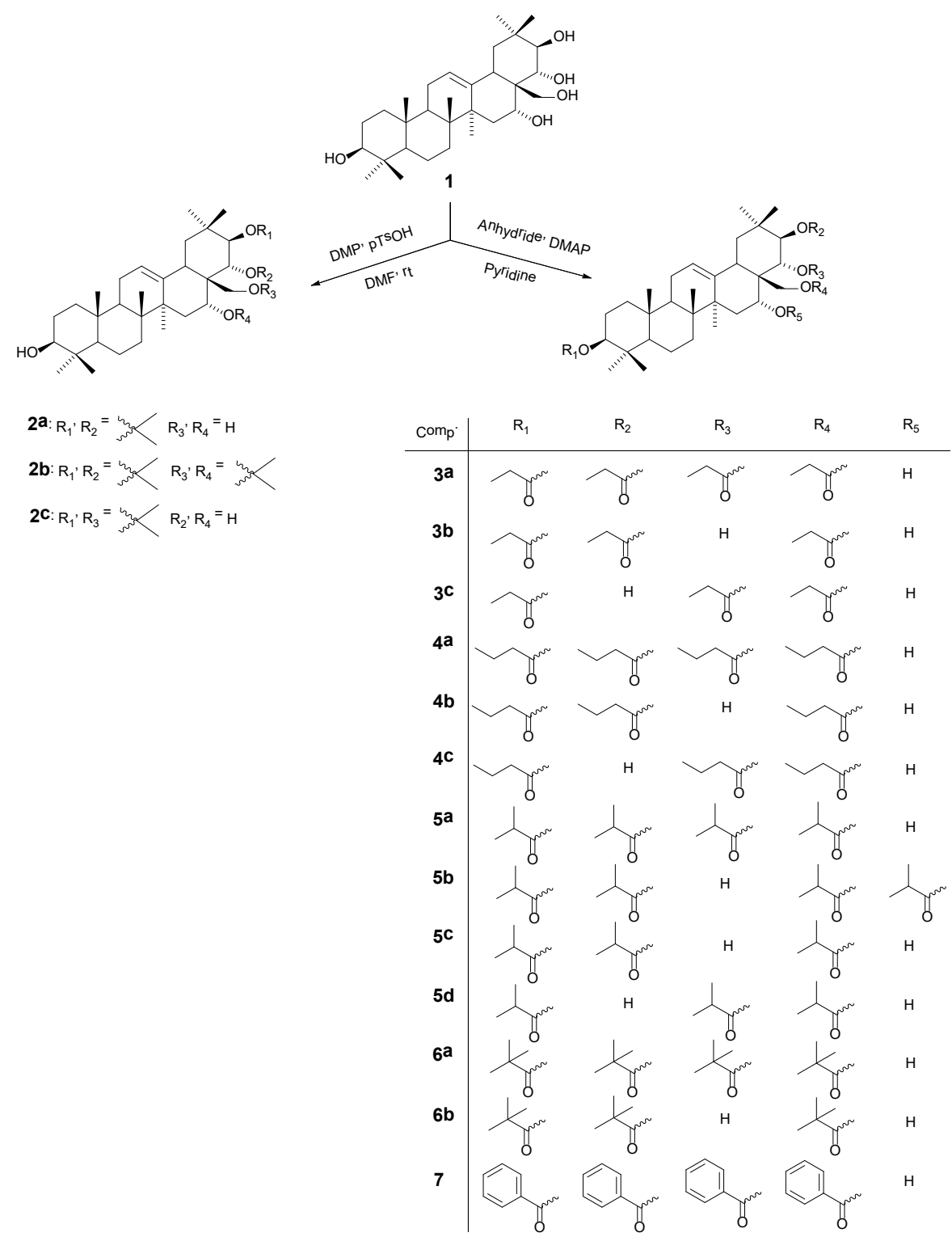

Scheme 1. Synthetic pathway for barringtogenol $\mathrm{C}$ derivatives.

cytotoxic activity against four cell lines ( $\mathrm{CaCo}-2$, HeLa, MCF-7, and U87MG) at below $100 \mu \mathrm{M}$ concentration. Compounds $2 c, 3 a, 5 d$ and 7 showed activity only on one cancer cell line (CaCo-2, U87MG, U87MG and MCF-7), respectively. Remaining derivatives are not active at $100 \mu \mathrm{M}$ concentration (the highest dose tested). Within these series of compounds, 3a displayed considerable activity against U87MG cell line $\left(\mathrm{IC}_{50}=0.45 \mu \mathrm{M}\right)$. While compound 1 is not active on these cell lines, the inhibitory activity of 3 a was 26 times more potent than that of doxorubicin $\left(\mathrm{IC}_{50}=11.9 \mu \mathrm{M}\right)$. Similarly, compounds $2 a(5.28 \mu \mathrm{M}), 2 b(6.24 \mu \mathrm{M})$, 3b $(6.08 \mu \mathrm{M})$, and $3 c(4.25 \mu \mathrm{M})$ exhibited more potent activity than doxorubicin on the same cell lines. For the MCF-7 cell line, it was found that the most active compound was $2 \mathrm{~b}\left(\mathrm{IC}_{50}=5.19 \mu \mathrm{M}\right)$, followed closely by $7\left(\mathrm{IC}_{50}=6.40 \mu \mathrm{M}\right)$, were both more active than Doxorubicin. $2 \mathrm{~b}$ and 7 also exhibited a better cytotoxic profile than compared with compound 1 . For the $\mathrm{CaCo}-2$ cell line, the most active compound was $2 \mathrm{C}\left(\mathrm{IC}_{50}=14.3 \mu \mathrm{M}\right)$ which exhibited a 1.5-fold increase in comparison with doxorubicin and compound 1. Moreover, 2a $\left(\mathrm{IC}_{50}=26.6 \mu \mathrm{M}\right)$ and $2 \mathrm{~b}\left(\mathrm{IC}_{50}=18.8 \mu \mathrm{M}\right)$, also showed moderate activity on these cells. While the inhibitory activity of $2 \mathrm{~b}\left(\mathrm{IC}_{50}=17.0 \mu \mathrm{M}\right)$ was 1.2 times more potent than that of doxorubicin, compound 
Table 1. Cytotoxic activity of compound 1 derivatives $2 a-c, 3 a-c, 4 a-c, 5 a-d, 6 a, b$ and 7 on cell lines after $48 \mathrm{~h}$ of exposure.

\begin{tabular}{|c|c|c|c|c|c|c|}
\hline $\begin{array}{l}\text { Cell Lines } \\
\mathrm{IC}_{50}(\mu \mathrm{M})\end{array}$ & Vero & $\mathrm{CaCo}-2$ & HeLa & MCF-7 & A549 & U87MG \\
\hline Doxorubicin & 12.8 & 20.0 & 20.0 & $>50.0$ & 9.94 & 11.9 \\
\hline 1 & 10.2 & 22.4 & 9.79 & 33.3 & - & - \\
\hline $2 a$ & 61.3 & 26.6 & 60.7 & 76.3 & - & 5.28 \\
\hline $2 b$ & 34.0 & 18.8 & 17.0 & 5.19 & 34.7 & 6.24 \\
\hline $2 c$ & - & 14.3 & - & - & - & - \\
\hline $3 a$ & - & - & - & - & - & 0.45 \\
\hline $3 b$ & - & 58.9 & 34.8 & 72.9 & 76.0 & 6.08 \\
\hline $3 c$ & 12.5 & 48.2 & 22.5 & 60.3 & 36.5 & 4.25 \\
\hline $4 a$ & - & - & - & - & - & - \\
\hline $4 b$ & - & - & - & - & - & - \\
\hline $4 c$ & - & - & - & 70.6 & 70.3 & 64.6 \\
\hline $5 a$ & - & - & - & - & - & - \\
\hline $5 b$ & - & - & - & - & - & - \\
\hline $5 c$ & - & - & - & - & - & - \\
\hline $5 d$ & - & - & - & - & - & 26.0 \\
\hline $6 a$ & - & - & - & - & - & - \\
\hline $6 b$ & - & - & - & - & - & - \\
\hline 7 & - & - & - & 6.40 & - & - \\
\hline
\end{tabular}

$->100$

$3 \mathrm{c}\left(\mathrm{IC}_{50}=22.5 \mu \mathrm{M}\right)$ showed moderate cytotoxic activity against HeLa cells. Also, for the A549 cell line, compound $2 \mathrm{~b}\left(\mathrm{IC}_{50}=34.7 \mu \mathrm{M}\right)$ showed some cytotoxic activity despite compound 1 was not exhibited activity on this cells.

In addition, the cytotoxic effect of the compounds $\mathbf{2 a - c}, \mathbf{3 a - c}, \mathbf{4 a - c}, \mathbf{5 a - d}, \mathbf{6 a}, \mathbf{b}$ and $\mathbf{7}$ were also tested on Vero cells and their effect on Vero cells growth is given in Table 1. Only compounds $\mathbf{2 a}, \mathbf{2} \mathbf{b}$ and $\mathbf{3 c}$ were found to be toxic to the growth of normal cells tested under in vitro conditions within all compounds examined.

\section{Experimental}

\section{General Considerations}

The reagents and solvents were purchased from Sigma-Aldrich, Merck and Alfa Aesar and were used as received. Column chromatography was performed on Silica gel $60(0.063-0.200 \mathrm{~mm}$,
Merck) ${ }^{1} \mathrm{H}$ NMR $(400 \mathrm{MHz})$ and ${ }^{13} \mathrm{C}$ NMR $(100 \mathrm{MHz}$ or $150 \mathrm{MHz}$ ) spectra were acquired on a Varian AS 400 Mercury or Bruker Avance III HD Ascend 600 $\mathrm{ULH}$ spectrometer with $\mathrm{CDCl}_{3}$ as solvent and tetramethylsilane (TMS) as internal standard. Chemical shifts $(\delta)$ were reported in units $(\mathrm{ppm})$ by assigning TMS resonance in the ${ }^{1} \mathrm{H}$ spectrum as $0.00 \mathrm{ppm}$ and $\mathrm{CDCl}_{3}$ resonance in the ${ }^{13} \mathrm{C}$ spectrum as $77.0 \mathrm{ppm}$. All coupling constants ( $J$ values) were reported in Hertz $(\mathrm{Hz})$. Elemental analyses were performed on a Perkin-Elmer PE 2400 elemental analyzer. FTIR spectra were recorded on a Perkin Elmer Spectrum 100 series. Mass spectra were acquired using a Bruker HCT UItra Ion Trap Mass Spectrometer.

\section{Plant Material}

Pericarps of fruits of $S$. officinalis $L$. were collected in August 2011 in Kusadasi (Aydın, Turkey). A voucher specimen has been deposited in the herbarium of the Botanic Garden of Ege University. 


\section{Extraction}

Air-dried powdered pericarps of fruits $(500 \mathrm{~g})$ were extracted with $\mathrm{MeOH}(2 \times 4 \mathrm{~L})$. After filtration, the solvent was removed by rotary evaporation yielding $50 \mathrm{~g}$ of extract. The $\mathrm{MeOH}$ extract was dissolved in $\mathrm{H}_{2} \mathrm{O}(350 \mathrm{~mL})$, and successively partitioned with hexane $(2 \times 200 \mathrm{~mL})$, EtOAc $(2 \times 200$ $\mathrm{mL})$ and $n-\mathrm{BuOH}$ saturated with $\mathrm{H}_{2} \mathrm{O}(3 \times 200 \mathrm{~mL})$. The $n$-BuOH extract $(20 \mathrm{~g})$ was separately dissolved in $2 \mathrm{~L} \mathrm{MeOH/2N} \mathrm{HCl} \mathrm{(1:1)} \mathrm{and} \mathrm{refluxed} \mathrm{for} 6$ h. After cooling, the solution was hydrolysed with $33 \% \mathrm{KOH}$ at $100^{\circ} \mathrm{C}$ for $6 \mathrm{~h}$. The reaction mixture was neutralized to $\mathrm{pH} 7$ with $2 \mathrm{~N} \mathrm{HCl}$ and extracted with EtOAc. The mixture was purified by $\mathrm{CC}$ using silica gel and $\mathrm{CH}_{2} \mathrm{Cl}_{2}: \mathrm{MeOH}: \mathrm{H}_{2} \mathrm{O}$ (90:10:1) as eluent to afford barringtogenol C (6 g), which was identified by NMR analyses, and by comparison with literature data [48].

\section{Olean-12-ene-3,16,21,22,28-pentol (1):}

Amorphous white solid; IR $v_{\text {max }}^{\mathrm{KBr}} \mathrm{cm}^{-1}: 3430(>\mathrm{OH})$, 2948 (>CH), $1656(\mathrm{C}=\mathrm{C}) ;{ }^{1} \mathrm{H}$ NMR (400 MHz, $\mathrm{CDCl}_{3}$ ) $\delta 5.17(1 \mathrm{H}, \mathrm{t}, \mathrm{J}=3.5 \mathrm{~Hz}, \mathrm{H}-12), 4.24(1 \mathrm{H}, \mathrm{br} \mathrm{s}, \mathrm{H}-16)$, $4.16(1 \mathrm{H}, \mathrm{s}, \mathrm{H}-21), 4.02(1 \mathrm{H}, \mathrm{s}, \mathrm{H}-22), 3.76(1 \mathrm{H}, \mathrm{d}$ $J=9.2 \mathrm{~Hz}, \mathrm{H}-28 \mathrm{a}), 3.58(1 \mathrm{H}, \mathrm{d}, \mathrm{J}=9.2 \mathrm{~Hz}, \mathrm{H}-28 \mathrm{~b})$, $2.98(1 \mathrm{H}, \mathrm{d}, \mathrm{J}=8.8, \mathrm{H}-3), 2.35(1 \mathrm{H}, \mathrm{m}, \mathrm{H}-19 \mathrm{a}), 2.30$ $(1 \mathrm{H}, \mathrm{m}, \mathrm{H}-18), 1.80(2 \mathrm{H}, \mathrm{m}, \mathrm{H}-11), 1.79(1 \mathrm{H}, \mathrm{m}, \mathrm{H}-2 \mathrm{a})$, $1.78(1 \mathrm{H}, \mathrm{m}, \mathrm{H}-15 \mathrm{a}), 1.58(1 \mathrm{H}, \mathrm{m}, \mathrm{H}-2 \mathrm{~b}), 1.56(1 \mathrm{H}, \mathrm{m}$, $\mathrm{H}-9), 1.54(1 \mathrm{H}, \mathrm{m}, \mathrm{H}-1 \mathrm{a}), 1.53(1 \mathrm{H}, \mathrm{m}, \mathrm{H}-7 \mathrm{a}), 1.53(1 \mathrm{H}$ m, H-6a), 1.42(1H, m, H-6b), $1.36(1 \mathrm{H}, \mathrm{m}, \mathrm{H}-15 \mathrm{~b}), 1.36$ (1H, m, H-7b), 1.33 (3H, s, H-27), 1.04 (1H, m, H-19b), $0.97(1 \mathrm{H}, \mathrm{m}, \mathrm{H}-1 \mathrm{~b}), 0.89(3 \mathrm{H}, \mathrm{s}, \mathrm{H}-29), 0.85(3 \mathrm{H}, \mathrm{s}$, $\mathrm{H}-30), 0.82(3 \mathrm{H}, \mathrm{s}, \mathrm{H}-23), 0.82(3 \mathrm{H}, \mathrm{s}, \mathrm{H}-25), 0.79$ $(1 \mathrm{H}, \mathrm{m}, \mathrm{H} 5), 0.79(3 \mathrm{H}, \mathrm{s}, \mathrm{H}-26), 0.66(3 \mathrm{H}, \mathrm{s}, \mathrm{H}-24)$, ${ }^{13} \mathrm{C}$ NMR (150 MHz, $\left.\mathrm{CDCl}_{3}\right) \delta 143.8(\mathrm{C}-13), 122.5(\mathrm{C}-$ 12), 77.6 (C-21), 77.5 (C-22), 74.8 (C-3), 67.3 (C-28), 66.0 (C-16), 55.6 (C-5), 46.6 (C-9), 46.6 (C-19), 46.0 (C-17), 41.4 (C-8), 40.5 (C-4), 39.9 (C-1), 38.5 (C-14), 37.9 (C-18), 37.0 (C-10), 36.4 (C-20), 33.6 (C15), 32.9 (C-7), 30.6 (C-29), 28.8 (C-27), 27.6 (C-23), 24.8 (C-11), 23.7 (C-2), 19.4 (C-30), 18.4 (C-6), 17.2 (C-24), 16.7 (C-26), 16.0 (C-25). ESI-MS (pos. ion mode) at $\mathrm{m} / \mathrm{z} 513[\mathrm{M}+\mathrm{Na}]^{+}, \mathrm{m} / \mathrm{z} 1003[2 \mathrm{M}+\mathrm{Na}]^{+}$.

\section{General procedures for the preparation of compounds 2a-c}

A mixture of 1 (100.0 mg, $0.2 \mathrm{mmol}$ ), 2,2-Dimethoxypropane $(0.5 \mathrm{ml}, 4 \mathrm{mmol})$ and p-Toluenesulfonic acid $(2.0 \mathrm{mg}, 0.01 \mathrm{mmol})$ was stirred in DMF (3.0 mL) at rt overnight. Saturated
$\mathrm{NaHCO}_{3}$ and EtOAc were added and the reaction mixture extracted, washed with water, dried over $\mathrm{Na}_{2} \mathrm{SO}_{4}$ and the solvent removed under reduced pressure. The residue was chromatographed using a silica gel column with the solvent system Hexane:EtOAc (80:20) to yield $\mathbf{2 a}$ (40mg), $\mathbf{2 b}$ (20 $\mathrm{mg}$ ) and $\mathbf{2 c}(15 \mathrm{mg})$.

\section{Olean-12-ene-3,16,21,22,28-pentol, cyclic 21,22-(1-methylethylidene acetal) (2a):}

Amorphous white solid; IR $v^{\mathrm{KBr}}{ }_{\max } \mathrm{cm}^{-1}: 3435(>\mathrm{OH})$, $2950(>\mathrm{CH}), 1650(\mathrm{C}=\mathrm{C}) ;{ }^{1} \mathrm{H}$ NMR (400 MHz, $\left.\mathrm{CDCl}_{3}\right)$ $\delta 5.29(1 \mathrm{H}, \mathrm{t}, \mathrm{J}=3.5 \mathrm{~Hz}, \mathrm{H}-12), 4.77(1 \mathrm{H}, \mathrm{br} \mathrm{s}, \mathrm{H}-16)$, $4.16(1 \mathrm{H}, \mathrm{d}, \mathrm{J}=10.0 \mathrm{~Hz}, \mathrm{H}-21), 3.74(1 \mathrm{H}, \mathrm{d}, \mathrm{J}=10.0$ $\mathrm{Hz}, \mathrm{H}-22), 3.56(1 \mathrm{H}, \mathrm{d}, \mathrm{J}=12.0 \mathrm{~Hz}, \mathrm{H}-28 \mathrm{a}), 3.35$ $(1 \mathrm{H}, \mathrm{d}, \mathrm{J}=12.0 \mathrm{~Hz}, \mathrm{H}-28 \mathrm{~b}), 3.23(1 \mathrm{H}, \mathrm{dd}, \mathrm{J}=8.8,6.4$ $\mathrm{Hz}, \mathrm{H}-3), 2.50(1 \mathrm{H}, \mathrm{m}, \mathrm{H}-19 \mathrm{a}), 2.10(1 \mathrm{H}, \mathrm{m}, \mathrm{H}-18)$, $1.85(2 \mathrm{H}, \mathrm{m}, \mathrm{H}-11), 1.60(1 \mathrm{H}, \mathrm{m}, \mathrm{H}-2 \mathrm{a}), 1.59(1 \mathrm{H}, \mathrm{m}$, $\mathrm{H}-15 a), 1.58(1 \mathrm{H}, \mathrm{m}, \mathrm{H}-2 \mathrm{~b}), 1.56(1 \mathrm{H}, \mathrm{m}, \mathrm{H}-9), 1.54$ $(1 \mathrm{H}, \mathrm{m}, \mathrm{H}-1 \mathrm{a}), 1.53(1 \mathrm{H}, \mathrm{m}, \mathrm{H}-7 \mathrm{a}), 1.53(1 \mathrm{H}, \mathrm{m}, \mathrm{H}-6 \mathrm{a})$, $1.48,1.45\left(\mathrm{C}\left(\mathrm{CH}_{3}\right)_{2}\right), 1.42(1 \mathrm{H}, \mathrm{m}, \mathrm{H}-6 \mathrm{~b}), 1.40(3 \mathrm{H}, \mathrm{s}$, $\mathrm{H}-27), 1.36(1 \mathrm{H}, \mathrm{m}, \mathrm{H}-15 \mathrm{~b}), 1.36(1 \mathrm{H}, \mathrm{m}, \mathrm{H}-7 \mathrm{~b}), 1.04$ (1H, m, H-19b), $0.97(1 \mathrm{H}, \mathrm{m}, \mathrm{H}-1 \mathrm{~b}), 1.02(3 \mathrm{H}, \mathrm{s}, \mathrm{H}-29)$, $0.99(3 \mathrm{H}, \mathrm{s}, \mathrm{H}-30), 0.99(3 \mathrm{H}, \mathrm{s}, \mathrm{H}-23), 0.87(3 \mathrm{H}, \mathrm{s}$, $\mathrm{H}-26), 0.82(3 \mathrm{H}, \mathrm{s}, \mathrm{H}-25), 0.79(1 \mathrm{H}, \mathrm{m}, \mathrm{H} 5), 0.78$ ( $3 \mathrm{H}, \mathrm{s}, \mathrm{H}-24),{ }^{13} \mathrm{C}$ NMR $\left(150 \mathrm{MHz}, \mathrm{CDCl}_{3}\right) \delta 143.8$ (C-13), $\left.122.5(\mathrm{C}-12), 100.9\left(\mathrm{C}_{\left(\mathrm{CH}_{3}\right.}\right)_{2}\right), 78.4(\mathrm{C}-3), 78.1$ (C-21), 72.3 (C-22), 70.5 (C-28), 67.2 (C-16), 54.5 (C5), 46.7 (C-19), 46.1 (C-9), 46.0 (C-17), 41.4 (C-8), 40.5 (C-4), 39.9 (C-1), 38.5 (C-14), 37.9 (C-18), 37.0 (C-10), 36.4 (C-20), 33.6 (C-15), 32.9 (C-7), 30.6 (C29), 29.2, $29.2\left(\mathrm{C}\left(\mathrm{CH}_{3}\right)_{2}\right), 27.4(\mathrm{C}-27), 27.6(\mathrm{C}-23)$, 24.8 (C-11), 23.7 (C-2), 19.4 (C-30), 18.4 (C-6), 17.1 (C-26), 15.8 (C-24), 15.7 (C-25). ESI-MS (pos. ione mode) at $\mathrm{m} / \mathrm{z} 553[\mathrm{M}+\mathrm{Na}]^{+}, \mathrm{m} / \mathrm{z} 1083[2 \mathrm{M}+\mathrm{Na}]^{+}$. Anal. (Found: $\mathrm{C}, 70.35 ; \mathrm{H}, 9.23$. Calc. For $\mathrm{C}_{33} \mathrm{H}_{54} \mathrm{O}_{5}$ : C, $70.56 ; \mathrm{H}, 9.30 \%)$.

\section{Olean-12-ene-3,16,21,22,28-pentol, cyclic 21,22,16,28-bis(1-methylethylidene acetal) (2b):}

Amorphous white solid; IR $v^{\mathrm{KBr}}{ }_{\max } \mathrm{cm}^{-1}: 3435(>\mathrm{OH})$, $2950(>\mathrm{CH}), 1650(\mathrm{C}=\mathrm{C}) ;{ }^{1} \mathrm{H}$ NMR (400 MHz, $\mathrm{CDCl}_{3}$ ) $\delta 5.35(1 \mathrm{H}, \mathrm{t}, \mathrm{J}=3.5 \mathrm{~Hz}, \mathrm{H}-12), 4.16(1 \mathrm{H}, \mathrm{br} \mathrm{s}, \mathrm{H}-16)$, $4.08(1 \mathrm{H}, \mathrm{d}, \mathrm{J}=10.0 \mathrm{~Hz}, \mathrm{H}-21), 3.95(1 \mathrm{H}, \mathrm{d}, \mathrm{J}=10.0 \mathrm{~Hz}$, $\mathrm{H}-22), 3.20(1 \mathrm{H}, \mathrm{dd}, \mathrm{J}=8.8,6.4 \mathrm{~Hz}, \mathrm{H}-3), 3.14(1 \mathrm{H}$, $\mathrm{d}, \mathrm{J}=8.8 \mathrm{~Hz}, \mathrm{H}-28 \mathrm{a}), 3.04(1 \mathrm{H}, \mathrm{d}, \mathrm{J}=8.8 \mathrm{~Hz}, \mathrm{H}-28 \mathrm{~b})$, $2.50(1 \mathrm{H}, \mathrm{m}, \mathrm{H}-19 \mathrm{a}), 2.11(1 \mathrm{H}, \mathrm{m}, \mathrm{H}-18), 1.86(2 \mathrm{H}, \mathrm{m}$, $\mathrm{H}-11), 1.62(1 \mathrm{H}, \mathrm{m}, \mathrm{H}-2 \mathrm{a}), 1.60(1 \mathrm{H}, \mathrm{m}, \mathrm{H}-15 \mathrm{a}), 1.58$ $(1 \mathrm{H}, \mathrm{m}, \mathrm{H}-2 b), 1.56(1 \mathrm{H}, \mathrm{m}, \mathrm{H}-9), 1.54(1 \mathrm{H}, \mathrm{m}, \mathrm{H}-1 \mathrm{a})$, 
$1.52(1 \mathrm{H}, \mathrm{m}, \mathrm{H}-7 \mathrm{a}), 1.51(1 \mathrm{H}, \mathrm{m}, \mathrm{H}-6 \mathrm{a}), 1.42(1 \mathrm{H}, \mathrm{m}$, $\mathrm{H}-6 \mathrm{~b}), 1.40$ (3H, s, H-27), $1.36(1 \mathrm{H}, \mathrm{m}, \mathrm{H}-15 \mathrm{~b}), 1.36$ $(1 \mathrm{H}, \mathrm{m}, \mathrm{H}-7 \mathrm{~b}), 1.25,1.25,1.22,1.22\left(2 \times \mathrm{C}\left(\mathrm{CH}_{3}\right)_{2}\right), 1.04$ (1H, m, H-19b), $0.97(1 \mathrm{H}, \mathrm{m}, \mathrm{H}-1 \mathrm{~b}), 1.02(3 \mathrm{H}, \mathrm{s}, \mathrm{H}-29)$ $0.99(3 \mathrm{H}, \mathrm{s}, \mathrm{H}-30), 0.99(3 \mathrm{H}, \mathrm{s}, \mathrm{H}-23), 0.87(3 \mathrm{H}, \mathrm{s}$, $\mathrm{H}-26), 0.82(3 \mathrm{H}, \mathrm{s}, \mathrm{H}-25), 0.79(1 \mathrm{H}, \mathrm{m}, \mathrm{H} 5), 0.78($ $3 \mathrm{H}, \mathrm{s}, \mathrm{H}-24),{ }^{13} \mathrm{C}$ NMR $\left(150 \mathrm{MHz}, \mathrm{CDCl}_{3}\right) \delta 141.1(\mathrm{C}$ $13), 124.7(\mathrm{C}-12), 108.5,100.2\left(2 \times \mathrm{C}\left(\mathrm{CH}_{3}\right)_{2}\right), 83.3$ (C-21), 79.3 (C-3), 78.0 (C-22), 70.8 (C-28), 63.7 (C16), 54.5 (C-5), 46.8 (C-19), 46.1 (C-9), 46.0 (C-17), 41.4 (C-8), $40.4(\mathrm{C}-4), 39.9$ (C-1), 38.6 (C-14), 37.9 (C-18), 37.0 (C-10), 36.4 (C-20), 33.5 (C-15), 32.9 (C7), 29.8 (C-29), 28.4 (C-27), 27.8, 27.8, 27.7, 27.7 $\left(2 \times \mathrm{C}\left(\mathrm{CH}_{3}\right)_{2}\right), 27.6(\mathrm{C}-23), 24.8(\mathrm{C}-11), 23.9(\mathrm{C}-30), 23.7$ (C-2), 18.4 (C-6), 17.4 (C-26), 17.3 (C-24), 16.0 (C-25). ESI-MS (pos. ione mode) at $\mathrm{m} / \mathrm{z} 593[\mathrm{M}+\mathrm{Na}]^{+}$. Anal. (Found: $\mathrm{C}, 75.51 ; \mathrm{H}, 14.12$. Calc. For $\mathrm{C}_{36} \mathrm{H}_{58} \mathrm{O}_{5}: \mathrm{C}, 75.75$; $\mathrm{H}, 14.01 \%)$

\section{Olean-12-ene-3,16,21,22,28-pentol, cyclic 21,28-(1-methylethylidene acetal) (2c):}

Amorphous white solid; IR $v^{\mathrm{KBr}}{ }_{\max } \mathrm{cm}^{-1}: 3435(>\mathrm{OH})$, $2950(>\mathrm{CH}), 1650$ ( $\mathrm{C}=\mathrm{C}) ;{ }^{1} \mathrm{H}$ NMR $\left(400 \mathrm{MHz}, \mathrm{CDCl}_{3}\right)$ $\delta 5.29(1 \mathrm{H}, \mathrm{t}, \mathrm{J}=3.5 \mathrm{~Hz}, \mathrm{H}-12), 4.58(1 \mathrm{H}, \mathrm{br} \mathrm{s}, \mathrm{H}-16)$, $4.29(1 \mathrm{H}, \mathrm{d}, \mathrm{J}=10.0 \mathrm{~Hz}, \mathrm{H}-21), 3.55(1 \mathrm{H}, \mathrm{d}, \mathrm{J}=10.0 \mathrm{~Hz}$ $\mathrm{H}-22), 3.50(1 \mathrm{H}, \mathrm{d}, J=11.6 \mathrm{~Hz}, \mathrm{H}-28 \mathrm{a}), 3.26(1 \mathrm{H}, \mathrm{d}$, $\mathrm{J}=11.6 \mathrm{~Hz}, \mathrm{H}-28 \mathrm{~b}), 3.23(1 \mathrm{H}, \mathrm{dd}, \mathrm{J}=10.0,6.0 \mathrm{~Hz}, \mathrm{H}-3)$ $2.40(1 \mathrm{H}, \mathrm{m}, \mathrm{H}-19 \mathrm{a}), 2.10(1 \mathrm{H}, \mathrm{m}, \mathrm{H}-18), 1.85(2 \mathrm{H}, \mathrm{m}$, $\mathrm{H}-11), 1.60(1 \mathrm{H}, \mathrm{m}, \mathrm{H}-2 \mathrm{a}), 1.59(1 \mathrm{H}, \mathrm{m}, \mathrm{H}-15 \mathrm{a}), 1.58(1 \mathrm{H}$, $\mathrm{m}, \mathrm{H}-2 \mathrm{~b}), 1.56(1 \mathrm{H}, \mathrm{m}, \mathrm{H}-9), 1.54(1 \mathrm{H}, \mathrm{m}, \mathrm{H}-1 \mathrm{a}), 1.52$ (1H, m, H-7a), $1.53(1 \mathrm{H}, \mathrm{m}, \mathrm{H}-6 \mathrm{a}), 1.42(1 \mathrm{H}, \mathrm{m}, \mathrm{H}-6 \mathrm{~b})$ $1.40(3 \mathrm{H}, \mathrm{s}, \mathrm{H}-27), 1.36(1 \mathrm{H}, \mathrm{m}, \mathrm{H}-15 \mathrm{~b}), 1.36(1 \mathrm{H}, \mathrm{m}$,

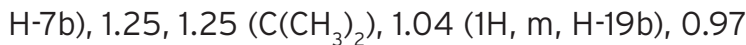
(1H, m, H-1b), $1.02(3 \mathrm{H}, \mathrm{s}, \mathrm{H}-29), 0.99$ (3H, s, H-30), $0.99(3 \mathrm{H}, \mathrm{s}, \mathrm{H}-23), 0.87(3 \mathrm{H}, \mathrm{s}, \mathrm{H}-26), 0.82(3 \mathrm{H}, \mathrm{s}$, $\mathrm{H}-25), 0.79(1 \mathrm{H}, \mathrm{m}, \mathrm{H} 5), 0.78(3 \mathrm{H}, \mathrm{s}, \mathrm{H}-24),{ }^{13} \mathrm{C} \mathrm{NMR}$ $\left(150 \mathrm{MHz}, \mathrm{CDCl}_{3}\right) \delta 140.6$ (C-13), 124.6 (C-12), 109.2 $\left(\mathrm{C}\left(\mathrm{CH}_{3}\right)_{2}\right), 82.9(\mathrm{C}-21), 82.5(\mathrm{C}-22), 79.1(\mathrm{C}-3), 72.5$ (C-28), 67.9 (C-16), 55.4 (C-5), 46.7 (C-19), 46.1 (C-9), 46.0 (C-17), 41.4 (C-8), 40.5 (C-4), 39.9 (C-1), 38.5 (C-14), 37.9 (C-18), 37.0 (C-10), $36.4(C-20), 33.6$ (C-15), 32.9 (C-7), 30.6 (C-29), 28.3 (C-27), 27.6 (C-

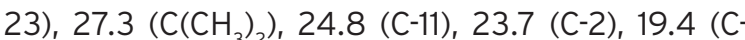
30), 18.4 (C-6), 17.5 (C-24), 17.1 (C-26), 15.8 (C-25). ESI-MS (pos. ione mode) at $\mathrm{m} / \mathrm{z} 553[\mathrm{M}+\mathrm{Na}]^{+}, \mathrm{m} / \mathrm{z}$ $1083[2 \mathrm{M}+\mathrm{Na}]^{+}$. Anal. (Found: $\mathrm{C}, 70.32 ; \mathrm{H}, 9.41$. Calc. For $\left.\mathrm{C}_{33} \mathrm{H}_{54} \mathrm{O}_{5}: \mathrm{C}, 70.56 ; \mathrm{H}, 9.30 \%\right)$.

\section{General Procedures for the Preparation of Compounds 3a-c}

A solution of 1 (100.0 mg, $0.2 \mathrm{mmol})$, propionic anhydride $(0.128 \mu \mathrm{l}, 1 \mathrm{mmol})$, and DMAP $(12.0 \mathrm{mg}$, $0.099 \mathrm{mmol})$ in dry pyridine $(5 \mathrm{~mL})$ was stirred at $120^{\circ} \mathrm{C}$ for $4 \mathrm{~h}$. The reaction mixture was neutralized with $5 \% \mathrm{HCl}(100 \mathrm{ml})$ and extracted with EtOAc. The organic layer was dried over anhydrous $\mathrm{Na}_{2} \mathrm{SO}_{4}$ and concentrated to dryness under reduced pressure. The residue was chromatographed using a silica gel column with the solvent system Hexane: EtOAc (80:20) to yield 3a (30mg), 3b (20 $\mathrm{mg}$ ) and $3 \mathrm{c}(20 \mathrm{mg})$.

\section{Olean-12-ene-3,16,21,22,28-pentol, 3,21,22,28-tetrapropanoate (3a):}

Amorphous white solid; IR $v^{\mathrm{KBr}}{ }_{\max } \mathrm{cm}^{-1}: 3430(>\mathrm{OH})$, $2948(>\mathrm{CH}), 1730(\mathrm{C}=\mathrm{O}), 1656(\mathrm{C}=\mathrm{C}) ;{ }^{1} \mathrm{H}$ NMR (400 MHz, $\left.\mathrm{CDCl}_{3}\right) \delta 5.56(1 \mathrm{H}, \mathrm{d}, \mathrm{J}=10.4 \mathrm{~Hz}, \mathrm{H}-21)$, $5.46(1 \mathrm{H}, \mathrm{d}, \mathrm{J}=10.4 \mathrm{~Hz}, \mathrm{H}-22), 5.35(1 \mathrm{H}, \mathrm{t}, \mathrm{J}=3.5$ $\mathrm{Hz}, \mathrm{H}-12), 4.51(1 \mathrm{H}, \mathrm{dd}, \mathrm{J}=8.8,6.4 \mathrm{~Hz}, \mathrm{H}-3), 4.16$ (1H, br s, H-16), $3.68(1 \mathrm{H}, \mathrm{d}, \mathrm{J}=11.2 \mathrm{~Hz}, \mathrm{H}-28 \mathrm{a}), 3.61$ (1H, d, J=11.2 Hz, H-28b), 2.45 (1H, m, H-19a), 2.32, $2.31,2.30,2.29\left(4 \times \mathrm{OOCCH}_{2} \mathrm{CH}_{3}, \mathrm{q}, \mathrm{J}=7.5 \mathrm{~Hz}\right), 2.28$ $(1 \mathrm{H}, \mathrm{m}, \mathrm{H}-18), 1.90(2 \mathrm{H}, \mathrm{m}, \mathrm{H}-11), 1.85(1 \mathrm{H}, \mathrm{m}, \mathrm{H}-2 \mathrm{a})$, $1.82(1 \mathrm{H}, \mathrm{m}, \mathrm{H}-15 \mathrm{a}), 1.68(1 \mathrm{H}, \mathrm{m}, \mathrm{H}-2 \mathrm{~b}), 1.66(1 \mathrm{H}, \mathrm{m}$, $\mathrm{H}-9), 1.62(1 \mathrm{H}, \mathrm{m}, \mathrm{H}-1 \mathrm{a}), 1.62(1 \mathrm{H}, \mathrm{m}, \mathrm{H}-7 \mathrm{a}), 1.56(1 \mathrm{H}$, $m, H-6 a), 1.42(1 \mathrm{H}, \mathrm{m}, \mathrm{H}-6 \mathrm{~b}), 1.41(3 \mathrm{H}, \mathrm{s}, \mathrm{H}-27), 1.36$ $(1 \mathrm{H}, \mathrm{m}, \mathrm{H}-15 \mathrm{~b}), 1.36(1 \mathrm{H}, \mathrm{m}, \mathrm{H}-7 \mathrm{~b}), 1.16,1.15,1.14,1.13$ $\left(4 \times \mathrm{OOCCH}_{2} \mathrm{CH}_{3}, \mathrm{t}, \mathrm{J}=7.5 \mathrm{~Hz}\right), 1.05(3 \mathrm{H}, \mathrm{s}, \mathrm{H}-23)$, $1.04(1 \mathrm{H}, \mathrm{m}, \mathrm{H}-19 \mathrm{~b}), 0.97(3 \mathrm{H}, \mathrm{s}, \mathrm{H}-25), 0.97(1 \mathrm{H}$, $\mathrm{m}, \mathrm{H}-1 \mathrm{~b}), 0.93(3 \mathrm{H}, \mathrm{s}, \mathrm{H}-29), 0.93(3 \mathrm{H}, \mathrm{s}, \mathrm{H}-26)$, $0.90(3 \mathrm{H}, \mathrm{s}, \mathrm{H}-30), 0.85(3 \mathrm{H}, \mathrm{s}, \mathrm{H}-24), 0.79(1 \mathrm{H}, \mathrm{m}$, $\mathrm{H} 5),{ }^{13} \mathrm{C} \mathrm{NMR}\left(150 \mathrm{MHz}, \mathrm{CDCl}_{3}\right) \delta 174.4,174.4,174.1$, $173.6(4 \times C=0), 140.8(C-13), 124.9(C-12), 80.6(C-$ 3), $78.4(\mathrm{C}-21), 73.5(\mathrm{C}-22), 69.0(\mathrm{C}-28), 66.3$ (C16), 46.7 (C-5), 46.6 (C-9), 46.6 (C-19), 46.0 (C-17), 41.4 (C-8), 40.5 (C-4), 39.9 (C-1), 38.5 (C-14), 37.9 (C-18), 37.0 (C-10), 36.4 (C-20), 33.6 (C-15), 32.9 (C-7), 29.0 (C-29), 28.3 (C-27), 28.3 (C-23), 27.9, 27.8, 27.7, $27.1\left(4 \times \mathrm{OOCCH}_{2} \mathrm{CH}_{3}\right), 24.8(\mathrm{C}-11), 23.7$ (C-2), 19.6 (C-30), 18.4 (C-6), 17.0 (C-24), 16.9 (C26), 15.8 (C-25), 9.5, 9.5, 9.4, $9.3\left(4 \times \mathrm{OOCCH}_{2} \mathrm{CH}_{3}\right)$. ESI-MS (pos. ione mode) $\mathrm{m} / \mathrm{z} 737[\mathrm{M}+\mathrm{Na}]^{+}, \mathrm{MS} /$ $\mathrm{MS} \mathrm{m} / \mathrm{z} 663\left[\mathrm{M}+\mathrm{Na}-\mathrm{CH}_{3} \mathrm{CH}_{2} \mathrm{COOH}\right]^{+}, 589[\mathrm{M}+\mathrm{Na}-$ $\left.2\left(\mathrm{CH}_{3} \mathrm{CH}_{2} \mathrm{COOH}\right)\right]^{+}, 515\left[\mathrm{M}+\mathrm{Na}-3\left(\mathrm{CH}_{3} \mathrm{CH}_{2} \mathrm{COOH}\right)\right]^{+}$ and $441\left[\mathrm{M}+\mathrm{Na}-4\left(\mathrm{CH}_{3} \mathrm{CH}_{2} \mathrm{COOH}\right)\right]^{+}$. Anal. (Found: C, 70.25; $\mathrm{H}, 9.40$. Calc. For $\mathrm{C}_{42} \mathrm{H}_{66} \mathrm{O}_{9}: \mathrm{C}, 70.56 ; \mathrm{H}$, 9.30\%) 


\section{Olean-12-ene-3,16,21,22,28-pentol, 3,21,28-tripropanoate (3b):}

Amorphous white solid; IR $v^{\mathrm{KBr}}{ }_{\max } \mathrm{cm}^{-1}: 3433(>\mathrm{OH})$, 2948 (>CH), 1730 ( $\mathrm{C}=\mathrm{O}), 1655(\mathrm{C}=\mathrm{C}) ;{ }^{1} \mathrm{H}$ NMR (400 $\left.\mathrm{MHz}, \mathrm{CDCl}_{3}\right) \delta 5.38(1 \mathrm{H}, \mathrm{d}, \mathrm{J}=10.0 \mathrm{~Hz}, \mathrm{H}-21), 5.35$ $(1 \mathrm{H}, \mathrm{t}, \mathrm{J}=3.5 \mathrm{~Hz}, \mathrm{H}-12), 4.51(1 \mathrm{H}, \mathrm{dd}, \mathrm{J}=8.8,6.4 \mathrm{~Hz}$, $\mathrm{H}-3), 4.27(1 \mathrm{H}, \mathrm{br} \mathrm{s}, \mathrm{H}-16), 3.89(1 \mathrm{H}, \mathrm{d}, \mathrm{J}=10.0 \mathrm{~Hz}$ $H-22), 3.89(1 \mathrm{H}, \mathrm{d}, J=10.8 \mathrm{~Hz}, \mathrm{H}-28 \mathrm{a}), 3.80(1 \mathrm{H}, \mathrm{d}$ $\mathrm{J}=10.8 \mathrm{~Hz}, \mathrm{H}-28 \mathrm{~b}), 2.43(1 \mathrm{H}, \mathrm{m}, \mathrm{H}-19 \mathrm{a}), 2.39,2.38$, 2.37, $\left(3 \times \mathrm{OOCCH}_{2} \mathrm{CH}_{3}, \mathrm{q}, \mathrm{J}=7.5 \mathrm{~Hz}\right), 2.26(1 \mathrm{H}, \mathrm{m}$, $\mathrm{H}-18), 1.93(2 \mathrm{H}, \mathrm{m}, \mathrm{H}-11), 1.84(1 \mathrm{H}, \mathrm{m}, \mathrm{H}-2 \mathrm{a}), 1.80$ (1H, m, H-15a), $1.67(1 \mathrm{H}, \mathrm{m}, \mathrm{H}-2 \mathrm{~b}), 1.64(1 \mathrm{H}, \mathrm{m}, \mathrm{H}-9)$, $1.63(1 \mathrm{H}, \mathrm{m}, \mathrm{H}-1 \mathrm{a}), 1.60(1 \mathrm{H}, \mathrm{m}, \mathrm{H}-7 \mathrm{a}), 1.57(1 \mathrm{H}, \mathrm{m}$, $\mathrm{H}-6 \mathrm{a}), 1.43(1 \mathrm{H}, \mathrm{m}, \mathrm{H}-6 \mathrm{~b}), 1.40(3 \mathrm{H}, \mathrm{s}, \mathrm{H}-27), 1.37$ $(1 \mathrm{H}, \mathrm{m}, \mathrm{H}-15 \mathrm{~b}), 1.36(1 \mathrm{H}, \mathrm{m}, \mathrm{H}-7 \mathrm{~b}), 1.19,1.18,1.16$ $\left(3 \times \mathrm{OOCCH}_{2} \mathrm{CH}_{3}, \mathrm{t}, \mathrm{J}=7.5 \mathrm{~Hz}\right), 1.04(3 \mathrm{H}, \mathrm{s}, \mathrm{H}-23)$, $1.03(1 \mathrm{H}, \mathrm{m}, \mathrm{H}-19 \mathrm{~b}), 0.98(3 \mathrm{H}, \mathrm{s}, \mathrm{H}-25), 0.97(1 \mathrm{H}$ $\mathrm{m}, \mathrm{H}-1 \mathrm{~b}), 0.94(3 \mathrm{H}, \mathrm{s}, \mathrm{H}-29), 0.93(3 \mathrm{H}, \mathrm{s}, \mathrm{H}-26)$, $0.91(3 \mathrm{H}, \mathrm{s}, \mathrm{H}-30), 0.84(3 \mathrm{H}, \mathrm{s}, \mathrm{H}-24), 0.82(1 \mathrm{H}, \mathrm{m}$, $\mathrm{H} 5),{ }^{13} \mathrm{C}$ NMR $\left(150 \mathrm{MHz}, \mathrm{CDCl}_{3}\right) 176.1,174.5,174.3$ $(3 \times C=0), 141.1(C-13), 124.6(C-12), 81.3(C-21), 80.6$ (C-3), $73.2(\mathrm{C}-22), 68.4(\mathrm{C}-28), 66.8$ (C-16), 55.4 (C5), 46.9 (C-17), 46.7 (C-19), 46.5 (C-9), 41.4 (C-8), $40.0(C-4), 39.9(C-1), 38.5(C-14), 38.0(C-18), 37.0$ (C-10), 36.4 (C-20), 34.3 (C-15), 32.9 (C-7), 29.2 (C-29), $28.3(\mathrm{C}-23), 28.2(\mathrm{C}-27), 28.1,27.8,27.1$ $\left(3 \times \mathrm{OOCCH}_{2} \mathrm{CH}_{3}\right), 24.8(\mathrm{C}-11), 23.8(\mathrm{C}-2), 19.5(\mathrm{C}-$ 30), 18.4 (C-6), 17.1 (C-24), 16.9 (C-26), 15.8 (C-25), 9.5, 9.5, $9.4\left(3 \times \mathrm{OOCCH}_{2} \mathrm{CH}_{3}\right)$. ESI-MS (pos. ione mode) $\mathrm{m} / \mathrm{z} 681[\mathrm{M}+\mathrm{Na}]^{+}, \mathrm{MS} / \mathrm{MS} \mathrm{m} / \mathrm{z} 607[\mathrm{M}+\mathrm{Na}-$ $\left.\mathrm{CH}_{3} \mathrm{CH}_{2} \mathrm{COOH}\right]^{+}, \quad 533 \quad\left[\mathrm{M}+\mathrm{Na}-2\left(\mathrm{CH}_{3} \mathrm{CH}_{2} \mathrm{COOH}\right)\right]^{+}$, $459\left[\mathrm{M}+\mathrm{Na}-3\left(\mathrm{CH}_{3} \mathrm{CH}_{2} \mathrm{COOH}\right)\right]^{+}$. Anal. (Found: C, 71.35; $\mathrm{H}, 9.35$. Calc. For $\mathrm{C}_{39} \mathrm{H}_{62} \mathrm{O}_{8}: \mathrm{C}, 71.09 ; \mathrm{H}$, 9.48\%).

\section{Olean-12-ene-3,16,21,22,28-pentol, 3,22,28-tripropanoate (3c):}

Amorphous white solid; IR $v^{\mathrm{KBr}}{ }_{\max } \mathrm{Cm}^{-1}: 3430(>\mathrm{OH})$, $2948(>\mathrm{CH}), 1732$ ( $\mathrm{C}=0), 1656(\mathrm{C}=\mathrm{C}) ;{ }^{1} \mathrm{H}$ NMR (400 $\left.\mathrm{MHz}, \mathrm{CDCl}_{3}\right) \delta 5.27(1 \mathrm{H}, \mathrm{d}, \mathrm{J}=9.6 \mathrm{~Hz}, \mathrm{H}-22), 5.35$ $(1 \mathrm{H}, \mathrm{t}, \mathrm{J}=3.5 \mathrm{~Hz}, \mathrm{H}-12), 4.50(1 \mathrm{H}, \mathrm{dd}, \mathrm{J}=8.8,6.4$ $\mathrm{Hz}, \mathrm{H}-3), 4.18(1 \mathrm{H}, \mathrm{br} \mathrm{s}, \mathrm{H}-16), 4.01(1 \mathrm{H}, \mathrm{d}, \mathrm{J}=9.6$ $\mathrm{Hz}, \mathrm{H}-21), 3.70(2 \mathrm{H}, \mathrm{s}, \mathrm{H}-28), 2.44(1 \mathrm{H}, \mathrm{m}, \mathrm{H}-19 \mathrm{a})$, $2.38,2.37,2.35,\left(3 \times \mathrm{OOCCH}_{2} \mathrm{CH}_{3}, \mathrm{q}, \mathrm{J}=7.5 \mathrm{~Hz}\right)$ $2.25(1 \mathrm{H}, \mathrm{m}, \mathrm{H}-18), 1.93(2 \mathrm{H}, \mathrm{m}, \mathrm{H}-11), 1.83(1 \mathrm{H}, \mathrm{m}$, $\mathrm{H}-2 \mathrm{a}), 1.81(1 \mathrm{H}, \mathrm{m}, \mathrm{H}-15 \mathrm{a}), 1.66(1 \mathrm{H}, \mathrm{m}, \mathrm{H}-2 \mathrm{~b}), 1.64$ $(1 \mathrm{H}, \mathrm{m}, \mathrm{H}-9), 1.62(1 \mathrm{H}, \mathrm{m}, \mathrm{H}-1 \mathrm{a}), 1.61(1 \mathrm{H}, \mathrm{m}, \mathrm{H}-7 \mathrm{a})$, $1.56(1 \mathrm{H}, \mathrm{m}, \mathrm{H}-6 \mathrm{a}), 1.44(1 \mathrm{H}, \mathrm{m}, \mathrm{H}-6 \mathrm{~b}), 1.41(3 \mathrm{H}, \mathrm{s}$, $\mathrm{H}-27), 1.37(1 \mathrm{H}, \mathrm{m}, \mathrm{H}-15 \mathrm{~b}), 1.35(1 \mathrm{H}, \mathrm{m}, \mathrm{H}-7 \mathrm{~b}), 1.19$, $1.18,1.18\left(3 \times \mathrm{OOCCH}_{2} \mathrm{CH}_{3}, \mathrm{t}, \mathrm{J}=7.5 \mathrm{~Hz}\right), 1.04(3 \mathrm{H}, \mathrm{s}$,
$\mathrm{H}-23), 1.02(1 \mathrm{H}, \mathrm{m}, \mathrm{H}-19 \mathrm{~b}), 0.99(3 \mathrm{H}, \mathrm{s}, \mathrm{H}-25), 0.97$ $(1 \mathrm{H}, \mathrm{m}, \mathrm{H}-1 \mathrm{~b}), 0.95$ (3H, s, H-29), $0.93(3 \mathrm{H}, \mathrm{s}, \mathrm{H}-26)$, $0.92(3 \mathrm{H}, \mathrm{s}, \mathrm{H}-30), 0.84(3 \mathrm{H}, \mathrm{s}, \mathrm{H}-24), 0.82(1 \mathrm{H}, \mathrm{m}$, $\mathrm{H} 5),{ }^{13} \mathrm{C}$ NMR $\left(150 \mathrm{MHz}, \mathrm{CDCl}_{3}\right) 175.3,174.4,174.1$ $(3 \times C=0), 140.0(C-13), 124.8(C-12), 80.7(C-3), 78.3$ (C-22), 76.4 (C-21), 69.4 (C-28), 66.3 (C-16), 55.5 (C-5), 46.9 (C-17), 46.8 (C-19), 46.0 (C-9), 41.3 (C8), 40.6 (C-4), 39.9 (C-1), 38.5 (C-4), 38.0 (C-18), 37.0 (C-10), 36.4 (C-20), 33.9 (C-15), 32.9 (C-7), 29.2 (C-29), 28.2, 28.2, $28.0\left(3 \times \mathrm{OOCCH}_{2} \mathrm{CH}_{3}\right), 27.8(\mathrm{C}-$ 23), 27.1 (C-27), 24.8 (C-11), 23.7 (C-2), 18.3 (C-6), $18.3(\mathrm{C}-30), 17.0(\mathrm{C}-24), 16.9$ (C-26), $15.8(\mathrm{C}-25)$, 9.5, 9.4, $9.2\left(3 \times \mathrm{OOCCH}_{2} \mathrm{CH}_{3}\right)$. ESI-MS (pos. ione mode) $\mathrm{m} / \mathrm{z} 681[\mathrm{M}+\mathrm{Na}]^{+}, \mathrm{MS} / \mathrm{MS} \mathrm{m} / \mathrm{z} 607[\mathrm{M}+\mathrm{Na}-$ $\left.\mathrm{CH}_{3} \mathrm{CH}_{2} \mathrm{COOH}\right]^{+}, \quad 533 \quad\left[\mathrm{M}+\mathrm{Na}-2\left(\mathrm{CH}_{3} \mathrm{CH}_{2} \mathrm{COOH}\right)\right]^{+}$, $459\left[\mathrm{M}+\mathrm{Na}-3\left(\mathrm{CH}_{3} \mathrm{CH}_{2} \mathrm{COOH}\right)\right]^{+}$. Anal. (Found: C, 71.41; $\mathrm{H}$, 9.30. Calc. For $\mathrm{C}_{39} \mathrm{H}_{62} \mathrm{O}: \mathrm{C}$, 71.09; $\mathrm{H}$, 9.48\%).

\section{General Procedures for the Preparation of Compounds $4 a-c$}

A solution of 1 (100.0 mg, $0.2 \mathrm{mmol})$, butyric anhydride $(0.245 \mu \mathrm{l}, 1,5 \mathrm{mmol})$, and DMAP $(12.0 \mathrm{mg}$, $0.099 \mathrm{mmol})$ in dry pyridine $(5 \mathrm{~mL})$ was stirred at $120^{\circ} \mathrm{C}$ for $4 \mathrm{~h}$. The reaction mixture was neutralized with $5 \% \mathrm{HCl}(100 \mathrm{ml})$ and extracted with EtOAc. The organic layer was dried over anhydrous $\mathrm{Na}_{2} \mathrm{SO}_{4}$ and concentrated to dryness under reduced pressure. The residue was chromatographed using a silica gel column with the solvent system Hexane: EtOAc (80:20) to yield 8 (32mg), 9 (20 $\mathrm{mg})$ and $10(18 \mathrm{mg})$.

\section{Olean-12-ene-3,16,21,22,28-pentol, 3,21,22,28-tetrabutanoate (4a):}

Amorphous white solid; IR $v^{\mathrm{KBr}}{ }_{\max } \mathrm{cm}^{-1}: 3432(>\mathrm{OH})$, $2950(>\mathrm{CH}), 1725(\mathrm{C}=\mathrm{O}), 1656(\mathrm{C}=\mathrm{C}) ;{ }^{1} \mathrm{H}$ NMR $(400$ $\left.\mathrm{MHz}, \mathrm{CDCl}_{3}\right) \delta 5.56(1 \mathrm{H}, \mathrm{d}, \mathrm{J}=10.0 \mathrm{~Hz}, \mathrm{H}-21), 5.48$ $(1 \mathrm{H}, \mathrm{d}, \mathrm{J}=10.0 \mathrm{~Hz}, \mathrm{H}-22), 5.34(1 \mathrm{H}, \mathrm{t}, \mathrm{J}=3.5 \mathrm{~Hz}$, $\mathrm{H}-12), 4.53(1 \mathrm{H}, \mathrm{dd}, \mathrm{J}=9.6,6.4 \mathrm{~Hz}, \mathrm{H}-3), 4.13(1 \mathrm{H}, \mathrm{br}$ s, H-16), $3.70(1 \mathrm{H}, \mathrm{d}, \mathrm{J}=10.8 \mathrm{~Hz}, \mathrm{H}-28 \mathrm{a}), 3.55(1 \mathrm{H}, \mathrm{d}$, $\mathrm{J}=10.8 \mathrm{~Hz}, \mathrm{H}-28 \mathrm{~b}), 2.45$ (1H, m, H-19a), 2.32, 2.31, $2.29,2.28\left(4 \times \mathrm{OOCCH}_{2} \mathrm{CH}_{2} \mathrm{CH}_{3}, \mathrm{t}, \mathrm{J}=7.5 \mathrm{~Hz}\right), 2.27$ $(1 \mathrm{H}, \mathrm{m}, \mathrm{H}-18), 1.90(2 \mathrm{H}, \mathrm{m}, \mathrm{H}-11), 1.86(1 \mathrm{H}, \mathrm{m}, \mathrm{H}-2 \mathrm{a})$, $1.82(1 \mathrm{H}, \mathrm{m}, \mathrm{H}-15 \mathrm{a}), 1.67(1 \mathrm{H}, \mathrm{m}, \mathrm{H}-2 \mathrm{~b}), 1.65(1 \mathrm{H}, \mathrm{m}$, $\mathrm{H}-9), 1.62(1 \mathrm{H}, \mathrm{m}, \mathrm{H}-1 \mathrm{a}), 1.63(1 \mathrm{H}, \mathrm{m}, \mathrm{H}-7 \mathrm{a}), 1.62,1.62$, $1.61,1.60\left(4 \times \mathrm{OOCCH}_{2} \mathrm{CH}_{2} \mathrm{CH}_{3}, \mathrm{~m}\right), 1.56(1 \mathrm{H}, \mathrm{m}, \mathrm{H}-6 \mathrm{a})$, $1.42(1 \mathrm{H}, \mathrm{m}, \mathrm{H}-6 \mathrm{~b}), 1.40(3 \mathrm{H}, \mathrm{s}, \mathrm{H}-27), 1.36(1 \mathrm{H}, \mathrm{m}$, $\mathrm{H}-15 \mathrm{~b}), 1.35$ (1H, m, H-7b), 1.05 (3H, s, H-23), 1.04 $(1 \mathrm{H}, \mathrm{m}, \mathrm{H}-19 \mathrm{~b}), 0.97(3 \mathrm{H}, \mathrm{s}, \mathrm{H}-25), 0.97(1 \mathrm{H}, \mathrm{m}, \mathrm{H}-1 \mathrm{~b})$, 
$0.93(3 \mathrm{H}, \mathrm{s}, \mathrm{H}-29), 0.93(3 \mathrm{H}, \mathrm{s}, \mathrm{H}-26), 0.90(3 \mathrm{H}, \mathrm{s}$, $\mathrm{H}-30), 0.89,0.88,0.87,0.87\left(4 \times 00 \mathrm{CCH}_{2} \mathrm{CH}_{2} \mathrm{CH}_{3}\right.$ $\mathrm{t}, \mathrm{J}=7.5 \mathrm{~Hz}), 0.85(3 \mathrm{H}, \mathrm{s}, \mathrm{H}-24), 0.79(1 \mathrm{H}, \mathrm{m}, \mathrm{H} 5),{ }^{13} \mathrm{C}$ NMR $\left(150 \mathrm{MHz}, \mathrm{CDCl}_{3}\right) \delta 173.7,173.6,173.3,172.8$ $(4 \times C=0), 140.8(C-13), 124.9(C-12), 80.6(C-3), 78.3$ (C-21), 73.2 (C-22), 69.1 (C-28), 65.9 (C-16), 55.4 (C5), 46.6 (C-9), 46.6 (C-19), 46.0 (C-17), 41.4 (C-8), 40.4 (C-4), 39.9 (C-1), 38.5 (C-14), 37.9 (C-18), 37.0 (C-10), 36.9, 36.6, 36.5, $36.5\left(4 \times \mathrm{OOCCH}_{2} \mathrm{CH}_{2} \mathrm{CH}_{3}\right)$ 36.4 (C-20), 33.7 (C-15), 32.9 (C-7), 29.1 (C-29), 28.3 (C-27), 28.3 (C-23), 24.8 (C-11), 23.7 (C-2), 19.6 (C$30), 18.8,18.7,18.7,18.5\left(4 \times \mathrm{OOCCH}_{2} \mathrm{CH}_{2} \mathrm{CH}_{3}\right), 18.4$ (C-6), 17.0 (C-24), 16.9 (C-26), 15.8 (C-25), 13.9, 13.9, $13.8,13.8\left(4 \times \mathrm{OOCCH}_{2} \mathrm{CH}_{2} \mathrm{CH}_{3}\right)$. ESI-MS (pos. ione mode) at $\mathrm{m} / \mathrm{z} 793$ [M+Na] $]^{+}$. Anal. (Found: $\mathrm{C}, 71.40$; $\mathrm{H}$, 9.75. Calc. For $\mathrm{C}_{46} \mathrm{H}_{74} \mathrm{O}$ : $\left.\mathrm{C}, 71.65 ; \mathrm{H}, 9.67 \%\right)$.

\section{Olean-12-ene-3,16,21,22,28-pentol, 3,21,28-tributanoate (4b):}

Amorphous white solid; IR $v^{\mathrm{KBr}}{ }_{\max } \mathrm{cm}^{-1}: 3432(>\mathrm{OH})$, $2948(>\mathrm{CH}), 1725(\mathrm{C}=\mathrm{O}), 1656(\mathrm{C}=\mathrm{C}) ;{ }^{1} \mathrm{H}$ NMR $(400$ $\left.\mathrm{MHz}, \mathrm{CDCl}_{3}\right) \delta 5.39(1 \mathrm{H}, \mathrm{d}, \mathrm{J}=10.0 \mathrm{~Hz}, \mathrm{H}-21), 5.35$ $(1 \mathrm{H}, \mathrm{t}, \mathrm{J}=3.5 \mathrm{~Hz}, \mathrm{H}-12), 4.50(1 \mathrm{H}, \mathrm{dd}, \mathrm{J}=8.8,6.4 \mathrm{~Hz}$ $\mathrm{H}-3), 4.30(1 \mathrm{H}, \mathrm{br} \mathrm{s}, \mathrm{H}-16), 3.89(1 \mathrm{H}, \mathrm{d}, \mathrm{J}=10.0 \mathrm{~Hz}$ $\mathrm{H}-22), 3.89(1 \mathrm{H}, \mathrm{d}, \mathrm{J}=10.8 \mathrm{~Hz}, \mathrm{H}-28 \mathrm{a}), 3.80(1 \mathrm{H}, \mathrm{d}$ $\mathrm{J}=10.8 \mathrm{~Hz}, \mathrm{H}-28 \mathrm{~b}), 2.42(1 \mathrm{H}, \mathrm{m}, \mathrm{H}-19 \mathrm{a}), 2.33,2.32$, $2.30\left(3 \times \mathrm{OOCCH}_{2} \mathrm{CH}_{2} \mathrm{CH}_{3}, \mathrm{t}, \mathrm{J}=7.5 \mathrm{~Hz}\right), 2.25(1 \mathrm{H}, \mathrm{m}$ $\mathrm{H}-18), 1.93(2 \mathrm{H}, \mathrm{m}, \mathrm{H}-11), 1.85(1 \mathrm{H}, \mathrm{m}, \mathrm{H}-2 \mathrm{a}), 1.81(1 \mathrm{H}$, $m, H-15 a), 1.67$ (1H, m, H-2b), 1.63 (1H, m, H-9), 1.62, $1.62,1.61\left(3 \times 00 \mathrm{CCH}_{2} \mathrm{CH}_{2} \mathrm{CH}_{3}, \mathrm{~m}\right), 1.61(1 \mathrm{H}, \mathrm{m}, \mathrm{H}-1 \mathrm{a})$, $1.60(1 \mathrm{H}, \mathrm{m}, \mathrm{H}-7 \mathrm{a}), 1.57(1 \mathrm{H}, \mathrm{m}, \mathrm{H}-6 \mathrm{a}), 1.43(1 \mathrm{H}, \mathrm{m}$, $\mathrm{H}-6 \mathrm{~b}), 1.40(3 \mathrm{H}, \mathrm{s}, \mathrm{H}-27), 1.36$ (1H, m, H-15b), 1.36 $(1 \mathrm{H}, \mathrm{m}, \mathrm{H}-7 \mathrm{~b}), 1.04(3 \mathrm{H}, \mathrm{s}, \mathrm{H}-23), 1.03(1 \mathrm{H}, \mathrm{m}, \mathrm{H}-19 \mathrm{~b})$, $0.98(3 \mathrm{H}, \mathrm{s}, \mathrm{H}-25), 0.97(1 \mathrm{H}, \mathrm{m}, \mathrm{H}-1 \mathrm{~b}), 0.94(3 \mathrm{H}, \mathrm{s}$, $\mathrm{H}-29), 0.93(3 \mathrm{H}, \mathrm{s}, \mathrm{H}-26), 0.91(3 \mathrm{H}, \mathrm{s}, \mathrm{H}-30), 0.89$, $0.88,0.87\left(3 \times \mathrm{OOCCH}_{2} \mathrm{CH}_{2} \mathrm{CH}_{3}, \mathrm{t}, \mathrm{J}=7.5 \mathrm{~Hz}\right), 0.84$ $(3 \mathrm{H}, \mathrm{s}, \mathrm{H}-24), 0.82(1 \mathrm{H}, \mathrm{m}, \mathrm{H} 5),{ }^{13} \mathrm{C}$ NMR $(150 \mathrm{MHz}$ $\left.\mathrm{CDCl}_{3}\right)$ 175.4, 173.7, $173.5(3 \times \mathrm{C}=0), 141.2(\mathrm{C}-13)$, 124.4 (C-12), 81.3 (C-21), 80.6 (C-3), 73.1 (C-22), 68.4 (C-28), 66.5 (C-16), 55.4 (C-5), 46.8 (C-17), 46.7 (C19), 46.6 (C-9), 41.3 (C-8), 40.1 (C-4), 39.9 (C-1), 38.5 (C-14), 38.0 (C-18), 37.0 (C-10), 36.9, 36.6, 36.5 $\left(3 \times \mathrm{OOCCH}_{2} \mathrm{CH}_{2} \mathrm{CH}_{3}\right), 36.5(\mathrm{C}-20), 34.4(\mathrm{C}-15), 32.9$ (C-7), 29.1 (C-29), 28.3 (C-23), 28.2 (C-27), 28.2, 27.8, $27.1\left(3 \times \mathrm{OOCCH}_{2} \mathrm{CH}_{3}\right), 24.8(\mathrm{C}-11), 23.8(\mathrm{C}-2)$, $19.5(\mathrm{C}-30), 18.8,18.7,18.7\left(3 \times \mathrm{OOCCH}_{2} \mathrm{CH}_{2} \mathrm{CH}_{3}\right)$ 18.4 (C-6), 17.1 (C-24), 16.9 (C-26), 15.8 (C-25), 13.9, $13.9,13.8\left(3 \times \mathrm{OOCCH}_{2} \mathrm{CH}_{2} \mathrm{CH}_{3}\right)$. ESI-MS (pos. ione mode) at $\mathrm{m} / \mathrm{z} 723[\mathrm{M}+\mathrm{Na}]^{+}$. Anal. (Found: $\mathrm{C}, 71.65$; $\mathrm{H}$, 9.60. Calc. For $\left.\mathrm{C}_{42} \mathrm{H}_{68} \mathrm{O}_{8}: \mathrm{C}, 71.96 ; \mathrm{H}, 9.77 \%\right)$.

\section{Olean-12-ene-3,16,21,22,28-pentol, 3,22,28-tributanoate (4c):}

Amorphous white solid; IR $v^{\mathrm{KBr}}{ }_{\max } \mathrm{Cm}^{-1}: 3430(>\mathrm{OH})$, $2948(>\mathrm{CH}), 1725(\mathrm{C}=\mathrm{O}), 1656(\mathrm{C}=\mathrm{C}) ;{ }^{1} \mathrm{H}$ NMR (400 $\left.\mathrm{MHz}, \mathrm{CDCl}_{3}\right) \delta 5.28(1 \mathrm{H}, \mathrm{d}, \mathrm{J}=10.0 \mathrm{~Hz}, \mathrm{H}-22), 5.34$ $(1 \mathrm{H}, \mathrm{t}, \mathrm{J}=3.5 \mathrm{~Hz}, \mathrm{H}-12), 4.50(1 \mathrm{H}, \mathrm{dd}, \mathrm{J}=8.8,6.4 \mathrm{~Hz}$, $\mathrm{H}-3), 4.14(1 \mathrm{H}, \mathrm{br} \mathrm{s}, \mathrm{H}-16), 4.00(1 \mathrm{H}, \mathrm{d}, \mathrm{J}=10.0 \mathrm{~Hz}$, $\mathrm{H}-21), 3.68(1 \mathrm{H}, \mathrm{d}, \mathrm{J}=11.2 \mathrm{~Hz}, \mathrm{H}-28 \mathrm{a}), 3.62(1 \mathrm{H}, \mathrm{d}$, $\mathrm{J}=11.2 \mathrm{~Hz}, \mathrm{H}-28 \mathrm{~b}), 2.42(1 \mathrm{H}, \mathrm{m}, \mathrm{H}-19 \mathrm{a}), 2.33,2.31$, $2.30\left(3 \times \mathrm{OOCCH}_{2} \mathrm{CH}_{2} \mathrm{CH}_{3}, \mathrm{t}, \mathrm{J}=7.5 \mathrm{~Hz}\right), 2.24(1 \mathrm{H}$, $\mathrm{m}, \mathrm{H}-18), 1.92(2 \mathrm{H}, \mathrm{m}, \mathrm{H}-11), 1.86(1 \mathrm{H}, \mathrm{m}, \mathrm{H}-2 \mathrm{a}), 1.81$ $(1 \mathrm{H}, \mathrm{m}, \mathrm{H}-15 \mathrm{a}), 1.66(1 \mathrm{H}, \mathrm{m}, \mathrm{H}-2 \mathrm{~b}), 1.63(1 \mathrm{H}, \mathrm{m}, \mathrm{H}-9)$, $1.63,1.62,1.61\left(3 \times \mathrm{OOCCH}_{2} \mathrm{CH}_{2} \mathrm{CH}_{3}, \mathrm{~m}\right), 1.61(1 \mathrm{H}, \mathrm{m}$, $\mathrm{H}-1 \mathrm{a}), 1.60(1 \mathrm{H}, \mathrm{m}, \mathrm{H}-7 \mathrm{a}), 1.58(1 \mathrm{H}, \mathrm{m}, \mathrm{H}-6 \mathrm{a}), 1.43$ $(1 \mathrm{H}, \mathrm{m}, \mathrm{H}-6 \mathrm{~b}), 1.41(3 \mathrm{H}, \mathrm{s}, \mathrm{H}-27), 1.37(1 \mathrm{H}, \mathrm{m}, \mathrm{H}-15 \mathrm{~b})$, $1.35(1 \mathrm{H}, \mathrm{m}, \mathrm{H}-7 \mathrm{~b}), 1.04(3 \mathrm{H}, \mathrm{s}, \mathrm{H}-23), 1.03(1 \mathrm{H}, \mathrm{m}$, $\mathrm{H}-19 \mathrm{~b}), 0.99$ (3H, s, H-25), 0.97 (1H, m, H-1b), 0.95 (3H, s, H-29), $0.93(3 \mathrm{H}, \mathrm{s}, \mathrm{H}-26), 0.91(3 \mathrm{H}, \mathrm{s}, \mathrm{H}-30)$, $0.90,0.88,0.87\left(3 \times \mathrm{OOCCH}_{2} \mathrm{CH}_{2} \mathrm{CH}_{3}, \mathrm{t}, \mathrm{J}=7.5 \mathrm{~Hz}\right)$, $0.86(3 \mathrm{H}, \mathrm{s}, \mathrm{H}-24), 0.84(1 \mathrm{H}, \mathrm{m}, \mathrm{H} 5),{ }^{13} \mathrm{C}$ NMR $(150$ $\left.\mathrm{MHz}, \mathrm{CDCl}_{3}\right)$ 175.4, 173.7, $173.5(3 \times \mathrm{C}=0), 141.2$ (C-13), 124.4 (C-12), 81.3 (C-21), $80.6(\mathrm{C}-3), 73.1$ (C-22), 68.4 (C-28), 66.5 (C-16), 55.4 (C-5), 46.8 (C-17), 46.7 (C-19), 46.6 (C-9), 41.3 (C-8), 40.1 (C4), 39.9 (C-1), 38.5 (C-14), 38.0 (C-18), $37.0(\mathrm{C}-10)$, $36.9,36.6,36.5\left(3 \times \mathrm{OOCCH}_{2} \mathrm{CH}_{2} \mathrm{CH}_{3}\right), 36.5(\mathrm{C}-$ 20), 34.4 (C-15), 32.9 (C-7), 29.1 (C-29), 28.3 (C23), $28.2(\mathrm{C}-27), 28.2,27.8,27.1\left(3 \times \mathrm{OOCCH}_{2} \mathrm{CH}_{3}\right)$, 24.8 (C-11), 23.8 (C-2), 19.5 (C-30), 18.8, 18.7, 18.7 $\left(3 \times 00 \mathrm{CCH}_{2} \mathrm{CH}_{2} \mathrm{CH}_{3}\right), 18.4(\mathrm{C}-6), 17.1(\mathrm{C}-24), 16.9(\mathrm{C}-$ 26), 15.8 (C-25), 13.9, 13.9, $13.8\left(3 \times \mathrm{OOCCH}_{2} \mathrm{CH}_{2} \mathrm{CH}_{3}\right)$. ESI-MS (pos. ione mode) at m/z $723[\mathrm{M}+\mathrm{Na}]^{+}$. Anal. (Found: $\mathrm{C}, 71.60 ; \mathrm{H}$, 9.85. Calc. For $\mathrm{C}_{42} \mathrm{H}_{68} \mathrm{O}_{8}$ : $\mathrm{C}$, 71.96; $\mathrm{H}, 9.77 \%$ ).

\section{General Procedures for the Preparation of Compounds 5a-d.}

A solution of $1(100.0 \mathrm{mg}, 0.2 \mathrm{mmol})$, isobutyric anhydride $(249 \mu \mathrm{l}, 1,5 \mathrm{mmol})$, and DMAP $(12.0 \mathrm{mg}$, $0.099 \mathrm{mmol}$ ) in dry pyridine $(5 \mathrm{ml})$ was stirred at $120^{\circ} \mathrm{C}$ for $4 \mathrm{~h}$. The reaction mixture was neutralized with $5 \% \mathrm{HCl}(100 \mathrm{ml})$ and extracted with EtOAc. The organic layer was dried over anhydrous $\mathrm{Na}_{2} \mathrm{SO}_{4}$ and concentrated to dryness under reduced pressure. The residue was chromatographed using a silica gel column with the solvent system Hexane: EtOAc (80:20) to yield 5a (25mg), 5b (15 $\mathrm{mg}, 5 \mathrm{c}(15 \mathrm{mg})$ and $5 \mathrm{~d}$ (15 mg). 


\section{Olean-12-ene-3,16,21,22,28-pentol, 3,21,22,28-tetra(2-methylpropanoate) (5a):}

Amorphous white solid; IR $\mathrm{n}^{\mathrm{KBr}}{ }_{\max } \mathrm{cm}^{-1}: 3432(>\mathrm{OH})$, $2945(>\mathrm{CH}), 1728(\mathrm{C}=\mathrm{O}), 1655(\mathrm{C}=\mathrm{C}) ;{ }^{1} \mathrm{H}$ NMR (400 $\left.\mathrm{MHz}, \mathrm{CDCl}_{3}\right) \delta 5.55(1 \mathrm{H}, \mathrm{d}, \mathrm{J}=10.4 \mathrm{~Hz}, \mathrm{H}-21), 5.53$ $(1 \mathrm{H}, \mathrm{d}, \mathrm{J}=10.4 \mathrm{~Hz}, \mathrm{H}-22), 5.34(1 \mathrm{H}, \mathrm{t}, \mathrm{J}=3.5 \mathrm{~Hz}$ $\mathrm{H}-12), 4.50(1 \mathrm{H}, \mathrm{dd}, \mathrm{J}=9.6,6.4 \mathrm{~Hz}, \mathrm{H}-3), 4.10(1 \mathrm{H}$ br s, H-16), $3.72(1 \mathrm{H}, \mathrm{d}, \mathrm{J}=10.8 \mathrm{~Hz}, \mathrm{H}-28 \mathrm{a}), 3.43$ $(1 \mathrm{H}, \mathrm{d}, \mathrm{J}=10.8 \mathrm{~Hz}, \mathrm{H}-28 \mathrm{~b}), 2.54,2.53,2.53,2.52$ $\left(4 \times \mathrm{OOCCH}\left(\mathrm{CH}_{3}\right)_{2}, \mathrm{~m}\right), 2.45(1 \mathrm{H}, \mathrm{m}, \mathrm{H}-19 \mathrm{a}), 2.27(1 \mathrm{H}$ $m, H-18), 1.91(2 \mathrm{H}, \mathrm{m}, \mathrm{H}-11), 1.87(1 \mathrm{H}, \mathrm{m}, \mathrm{H}-2 \mathrm{a}), 1.82$ (1H, m, H-15a), $1.67(1 \mathrm{H}, \mathrm{m}, \mathrm{H}-2 \mathrm{~b}), 1.65(1 \mathrm{H}, \mathrm{m}, \mathrm{H}-9)$, $1.65(1 \mathrm{H}, \mathrm{m}, \mathrm{H}-1 \mathrm{a}), 1.63(1 \mathrm{H}, \mathrm{m}, \mathrm{H}-7 \mathrm{a}), 1.56(1 \mathrm{H}, \mathrm{m}$, $\mathrm{H}-6 \mathrm{a}), 1.43$ (1H, m, H-6b), 1.40 (3H, s, H-27), 1.37 $(1 \mathrm{H}, \mathrm{m}, \mathrm{H}-15 \mathrm{~b}), 1.35(1 \mathrm{H}, \mathrm{m}, \mathrm{H}-7 \mathrm{~b}), 1.17,1.16,1.15,1.14$ $\left(4 \times \mathrm{OOCCH}\left(\mathrm{CH}_{3}\right)_{2}, \mathrm{~d}, \mathrm{~J}=6.8 \mathrm{~Hz}\right), 1.04(3 \mathrm{H}, \mathrm{s}, \mathrm{H}-23)$, $1.03(1 \mathrm{H}, \mathrm{m}, \mathrm{H}-19 \mathrm{~b}), 0.97(3 \mathrm{H}, \mathrm{s}, \mathrm{H}-25), 0.96(1 \mathrm{H}, \mathrm{m}$, $\mathrm{H}-1 \mathrm{~b}), 0.93(3 \mathrm{H}, \mathrm{s}, \mathrm{H}-29), 0.92(3 \mathrm{H}, \mathrm{s}, \mathrm{H}-26), 0.90$ $(3 \mathrm{H}, \mathrm{s}, \mathrm{H}-30), 0.82(3 \mathrm{H}, \mathrm{s}, \mathrm{H}-24), 0.81(1 \mathrm{H}, \mathrm{m}, \mathrm{H} 5)$, ${ }^{13} \mathrm{C}$ NMR $\left(150 \mathrm{MHz}, \mathrm{CDCl}_{3}\right) \delta 177.1,176.9,176.8$, $176.0(4 \times C=0), 140.8(C-13), 124.7(C-12), 80.4(C-$ 3), 78.1 (C-21), 72.4 (C-22), 69.3 (C-28), 65.1 (C-16), 55.4 (C-5), 46.7 (C-9), 46.6 (C-19), 46.1 (C-17), 41.5 (C-8), $40.3(\mathrm{C}-4), 39.8(\mathrm{C}-1), 38.5$ (C-14), 37.8 (C18), 37.0 (C-10), 36.4 (C-20), 34.8, 34.6, 34.5, 34.3 $\left(4 \times \mathrm{OOCCH}\left(\mathrm{CH}_{3}\right)_{2}\right), 33.7(\mathrm{C}-15), 32.8(\mathrm{C}-7), 29.1(\mathrm{C}-$ 29), 28.2 (C-27), 28.1 (C-23), 24.8 (C-11), 23.6 (C-2), $19.6(\mathrm{C}-30), 19.1,18.8,18.7,18.5\left(4 \times \mathrm{OOCCH}\left(\mathrm{CH}_{3}\right)_{2}\right)$, 18.4 (C-6), 17.0 (C-24), 16.9 (C-26), 15.9 (C-25). ESI-MS (pos. ione mode) at $\mathrm{m} / \mathrm{z} 793[\mathrm{M}+\mathrm{Na}]^{+}$. Anal. (Found: $\mathrm{C}, 71.80 ; \mathrm{H}, 9.80$. Calc. For $\mathrm{C}_{46} \mathrm{H}_{74} \mathrm{O}_{9}$ : C, $71.65 ; \mathrm{H}, 9.67 \%)$.

\section{Olean-12-ene-3,16,21,22,28-pentol, 3,16,21,28-tetra(2-methylpropanoate) (5b):}

Amorphous white solid; IR $v^{\mathrm{KBr}}{ }_{\max } \mathrm{cm}^{-1}: 3430(>\mathrm{OH})$, $2950(>\mathrm{CH}), 1728(\mathrm{C}=0), 1655(\mathrm{C}=\mathrm{C}) ;{ }^{1} \mathrm{H}$ NMR $(400$ $\left.\mathrm{MHz}, \mathrm{CDCl}_{3}\right) \delta 5.40(1 \mathrm{H}, \mathrm{br} \mathrm{s}, \mathrm{H}-16), 5.33(1 \mathrm{H}, \mathrm{t}, \mathrm{J}=3.5$ $\mathrm{Hz}, \mathrm{H}-12), 5.10(1 \mathrm{H}, \mathrm{d}, \mathrm{J}=10.0 \mathrm{~Hz}, \mathrm{H}-21), 4.50(1 \mathrm{H}, \mathrm{dd}$ $J=9.6,6.4 \mathrm{~Hz}, \mathrm{H}-3), 3.89(1 \mathrm{H}, \mathrm{d}, \mathrm{J}=10.0 \mathrm{~Hz}, \mathrm{H}-22)$, $3.80(1 \mathrm{H}, \mathrm{d}, \mathrm{J}=10.8 \mathrm{~Hz}, \mathrm{H}-28 \mathrm{a}), 3.70(1 \mathrm{H}, \mathrm{d}, \mathrm{J}=10.8$ $\mathrm{Hz}, \mathrm{H}-28 \mathrm{~b}), 2.55,2.54,2.53,2.52\left(4 \times \mathrm{OOCCH}\left(\mathrm{CH}_{3}\right)_{2}\right.$ m), $2.46(1 \mathrm{H}, \mathrm{m}, \mathrm{H}-19 \mathrm{a}), 2.28(1 \mathrm{H}, \mathrm{m}, \mathrm{H}-18), 1.91(2 \mathrm{H}$, $m, H-11), 1.87(1 \mathrm{H}, \mathrm{m}, \mathrm{H}-2 \mathrm{a}), 1.83(1 \mathrm{H}, \mathrm{m}, \mathrm{H}-15 \mathrm{a}), 1.68$ $(1 \mathrm{H}, \mathrm{m}, \mathrm{H}-2 \mathrm{~b}), 1.65(1 \mathrm{H}, \mathrm{m}, \mathrm{H}-9), 1.64(1 \mathrm{H}, \mathrm{m}, \mathrm{H}-1 \mathrm{a})$, $1.63(1 \mathrm{H}, \mathrm{m}, \mathrm{H}-7 \mathrm{a}), 1.57(1 \mathrm{H}, \mathrm{m}, \mathrm{H}-6 \mathrm{a}), 1.43(1 \mathrm{H}, \mathrm{m}$, $\mathrm{H}-6 \mathrm{~b}), 1.41(3 \mathrm{H}, \mathrm{s}, \mathrm{H}-27), 1.37(1 \mathrm{H}, \mathrm{m}, \mathrm{H}-15 \mathrm{~b}), 1.35$ $(1 \mathrm{H}, \mathrm{m}, \mathrm{H}-7 \mathrm{~b}), 1.16,1.15,1.14,1.13\left(4 \times \mathrm{OOCCH}\left(\mathrm{CH}_{3}\right)_{2^{\prime}}\right.$ $\mathrm{d}, \mathrm{J}=6.8 \mathrm{~Hz}), 1.04(3 \mathrm{H}, \mathrm{s}, \mathrm{H}-23), 1.02(1 \mathrm{H}, \mathrm{m}, \mathrm{H}-19 \mathrm{~b})$, $0.97(3 \mathrm{H}, \mathrm{s}, \mathrm{H}-25), 0.96(1 \mathrm{H}, \mathrm{m}, \mathrm{H}-1 \mathrm{~b}), 0.93(3 \mathrm{H}, \mathrm{s}$,
$\mathrm{H}-29), 0.92(3 \mathrm{H}, \mathrm{s}, \mathrm{H}-26), 0.90(3 \mathrm{H}, \mathrm{s}, \mathrm{H}-30), 0.87($ $3 \mathrm{H}, \mathrm{s}, \mathrm{H}-24), 0.85(1 \mathrm{H}, \mathrm{m}, \mathrm{H} 5),{ }^{13} \mathrm{C}$ NMR $(150 \mathrm{MHz}$, $\left.\mathrm{CDCl}_{3}\right) \delta 178.2,177.0,176.7,176.6(4 \times \mathrm{C}=0), 140.1$ (C-13), 125.4 (C-12), 80.4 (C-3), 79.6 (C-21), 72.4 (C22), 70.2 (C-28), 66.8 (C-16), 55.3 (C-5), 46.8 (C-9), 46.5 (C-19), 46.1 (C-17), 41.4 (C-8), 40.2 (C-4), 39.8 $(\mathrm{C}-1), 38.6(\mathrm{C}-14), 37.7(\mathrm{C}-18), 37.1(\mathrm{C}-10), 36.4$ (C20), 34.7, 34.6, 34.5, 34.3 $\left(4 \times \mathrm{OOCCH}\left(\mathrm{CH}_{3}\right)_{2}\right), 33.7$ (C-15), 32.7 (C-7), 29.1 (C-29), 28.1 (C-27), 28.0 (C23), 24.8 (C-11), 23.6 (C-2), 19.7 (C-30), 19.0, 18.8, 18.6, $18.5\left(4 \times \mathrm{OOCCH}\left(\mathrm{CH}_{3}\right)_{2}\right), 18.4(\mathrm{C}-6), 17.1(\mathrm{C}-24)$, 17.0 (C-26), 15.8 (C-25). ESI-MS (pos. ione mode) at $\mathrm{m} / \mathrm{z} 793[\mathrm{M}+\mathrm{Na}]^{+}$. Anal. (Found: $\mathrm{C}, 71.40 ; \mathrm{H}, 9.75$. Calc. For $\mathrm{C}_{46} \mathrm{H}_{74} \mathrm{O}_{9}$ : C, $\left.71.65 ; \mathrm{H}, 9.67 \%\right)$.

\section{Olean-12-ene-3,16,21,22,28-pentol, 3,21,28-tris(2-methylpropanoate) (5c):}

Amorphous white solid; IR $v^{\mathrm{KBr}}{ }_{\max } \mathrm{cm}^{-1}: 3430(>\mathrm{OH})$, $2948(>\mathrm{CH}), 1728(\mathrm{C}=0), 1656(\mathrm{C}=\mathrm{C}) ;{ }^{1} \mathrm{H}$ NMR (400 $\left.\mathrm{MHz}, \mathrm{CDCl}_{3}\right) \delta 5.41(1 \mathrm{H}, \mathrm{d}, \mathrm{J}=10.0 \mathrm{~Hz}, \mathrm{H}-21), 5.33(1 \mathrm{H}$, $t, J=3.5 \mathrm{~Hz}, \mathrm{H}-12), 4.50(1 \mathrm{H}, \mathrm{dd}, \mathrm{J}=9.6,6.4 \mathrm{~Hz}, \mathrm{H}-3)$, $4.15(1 \mathrm{H}, b r \mathrm{~s}, \mathrm{H}-16), 3.86(1 \mathrm{H}, \mathrm{d}, \mathrm{J}=10.0 \mathrm{~Hz}, \mathrm{H}-22)$, $3.86(1 \mathrm{H}, d, J=11.2 \mathrm{~Hz}, \mathrm{H}-28 \mathrm{a}), 3.77(1 \mathrm{H}, \mathrm{d}, \mathrm{J}=11.2$ $\mathrm{Hz}, \mathrm{H}-28 \mathrm{~b}), 2.60,2.58,2.57\left(3 \times \mathrm{OOCCH}\left(\mathrm{CH}_{3}\right)_{2}, \mathrm{~m}\right)$, $2.44(1 \mathrm{H}, \mathrm{m}, \mathrm{H}-19 \mathrm{a}), 2.28(1 \mathrm{H}, \mathrm{m}, \mathrm{H}-18), 1.90(2 \mathrm{H}, \mathrm{m}$, $H-11), 1.88(1 \mathrm{H}, \mathrm{m}, \mathrm{H}-2 \mathrm{a}), 1.83(1 \mathrm{H}, \mathrm{m}, \mathrm{H}-15 \mathrm{a}), 1.68$ $(1 \mathrm{H}, \mathrm{m}, \mathrm{H}-2 \mathrm{~b}), 1.65(1 \mathrm{H}, \mathrm{m}, \mathrm{H}-9), 1.64(1 \mathrm{H}, \mathrm{m}, \mathrm{H}-1 \mathrm{a})$, $1.63(1 \mathrm{H}, \mathrm{m}, \mathrm{H}-7 \mathrm{a}), 1.55(1 \mathrm{H}, \mathrm{m}, \mathrm{H}-6 \mathrm{a}), 1.43(1 \mathrm{H}, \mathrm{m}$, $\mathrm{H}-6 \mathrm{~b}), 1.41(3 \mathrm{H}, \mathrm{s}, \mathrm{H}-27), 1.37(1 \mathrm{H}, \mathrm{m}, \mathrm{H}-15 \mathrm{~b}), 1.35$ $(1 \mathrm{H}, \mathrm{m}, \mathrm{H}-7 \mathrm{~b}), 1.22,1.21,1.20\left(3 \times \mathrm{OOCCH}\left(\mathrm{CH}_{3}\right)_{2}, \mathrm{~d}\right.$, $\mathrm{J}=6.8 \mathrm{~Hz}), 1.04(3 \mathrm{H}, \mathrm{s}, \mathrm{H}-23), 1.03(1 \mathrm{H}, \mathrm{m}, \mathrm{H}-19 \mathrm{~b})$, $0.97(3 \mathrm{H}, \mathrm{s}, \mathrm{H}-25), 0.96(1 \mathrm{H}, \mathrm{m}, \mathrm{H}-1 \mathrm{~b}), 0.93(3 \mathrm{H}, \mathrm{s}$, $\mathrm{H}-29), 0.91(3 \mathrm{H}, \mathrm{s}, \mathrm{H}-26), 0.90(3 \mathrm{H}, \mathrm{s}, \mathrm{H}-30), 0.83$ ( $3 \mathrm{H}, \mathrm{s}, \mathrm{H}-24), 0.82(1 \mathrm{H}, \mathrm{m}, \mathrm{H} 5),{ }^{13} \mathrm{C}$ NMR $(150 \mathrm{MHz}$, $\left.\mathrm{CDCl}_{3}\right) \delta 178.7,177.0,176.9(3 \times \mathrm{C}=0), 141.2(\mathrm{C}-13)$, 124.4 (C-12), 80.4 (C-3), 81.2 (C-21), 73.0 (C-22), 68.4 (C-28), 66.5 (C-16), $55.4(\mathrm{C}-5), 46.8$ (C-9), 46.6 (C-19), 46.0 (C-17), 41.5 (C-8), 40.2 (C-4), 39.7 (C-1), 38.5 (C-14), 37.6 (C-18), $37.0(\mathrm{C}-10), 36.3$ (C$20), 34.7,34.6,34.5,\left(3 \times 00 C \mathrm{CH}\left(\mathrm{CH}_{3}\right)_{2}\right), 33.6(\mathrm{C}-$ 15), 32.8 (C-7), 29.1 (C-29), 28.2 (C-27), 28.0 (C-23), 24.7 (C-11), 23.5 (C-2), 19.6 (C-30), 19.1, 18.8, 18.7 $\left(3 \times \mathrm{OOCCH}\left(\mathrm{CH}_{3}\right)_{2}\right), 18.3(\mathrm{C}-6), 17.0(\mathrm{C}-24), 16.9(\mathrm{C}-$ 26), 16.0 (C-25). ESI-MS (pos. ione mode) at $\mathrm{m} / \mathrm{z}$ $723[\mathrm{M}+\mathrm{Na}]^{+}$. Anal. (Found: $\mathrm{C}, 71.80 ; \mathrm{H}, 9.65$. Calc. For $\left.\mathrm{C}_{42} \mathrm{H}_{68} \mathrm{O}_{8}: \mathrm{C}, 71.96 ; \mathrm{H}, 9.77 \%\right)$. 
Olean-12-ene-3,16,21,22,28-pentol, 3,22,28-tris(2-methylpropanoate) (5d):

Amorphous white solid; IR $v^{\mathrm{KBr}}{ }_{\max } \mathrm{Cm}^{-1}: 3430(>\mathrm{OH})$, $2948(>\mathrm{CH}), 1728$ ( $\mathrm{C}=\mathrm{O}), 1655(\mathrm{C}=\mathrm{C}) ;{ }^{1} \mathrm{H}$ NMR $(400$ $\left.\mathrm{MHz}, \mathrm{CDCl}_{3}\right) 5.33(1 \mathrm{H}, \mathrm{t}, \mathrm{J}=3.5 \mathrm{~Hz}, \mathrm{H}-12), \delta 5.27(1 \mathrm{H}, \mathrm{d}$ $\mathrm{J}=10.0 \mathrm{~Hz}, \mathrm{H}-22), 4.50(1 \mathrm{H}, \mathrm{dd}, \mathrm{J}=9.6,6.4 \mathrm{~Hz}, \mathrm{H}-3)$, $4.20(1 \mathrm{H}, \mathrm{br} \mathrm{s}, \mathrm{H}-16), 4.05(1 \mathrm{H}, \mathrm{d}, \mathrm{J}=10.0 \mathrm{~Hz}, \mathrm{H}-21)$ $3.70(1 \mathrm{H}, \mathrm{d}, \mathrm{J}=11.6 \mathrm{~Hz}, \mathrm{H}-28 \mathrm{a}), 3.50(1 \mathrm{H}, \mathrm{d}, \mathrm{J}=11.6$ $\mathrm{Hz}, \mathrm{H}-28 \mathrm{~b}), 2.60,2.59,2.57\left(3 \times \mathrm{OOCCH}\left(\mathrm{CH}_{3}\right)_{2}, \mathrm{~m}\right)$, $2.45(1 \mathrm{H}, \mathrm{m}, \mathrm{H}-19 \mathrm{a}), 2.29(1 \mathrm{H}, \mathrm{m}, \mathrm{H}-18), 1.91(2 \mathrm{H}, \mathrm{m}$, $\mathrm{H}-11), 1.87(1 \mathrm{H}, \mathrm{m}, \mathrm{H}-2 \mathrm{a}), 1.83(1 \mathrm{H}, \mathrm{m}, \mathrm{H}-15 \mathrm{a}), 1.67$ $(1 \mathrm{H}, \mathrm{m}, \mathrm{H}-2 \mathrm{~b}), 1.65(1 \mathrm{H}, \mathrm{m}, \mathrm{H}-9), 1.64(1 \mathrm{H}, \mathrm{m}, \mathrm{H}-1 \mathrm{a})$ $1.62(1 \mathrm{H}, \mathrm{m}, \mathrm{H}-7 \mathrm{a}), 1.55(1 \mathrm{H}, \mathrm{m}, \mathrm{H}-6 \mathrm{a}), 1.44(1 \mathrm{H}, \mathrm{m}$, $\mathrm{H}-6 \mathrm{~b}), 1.41(3 \mathrm{H}, \mathrm{s}, \mathrm{H}-27), 1.38(1 \mathrm{H}, \mathrm{m}, \mathrm{H}-15 \mathrm{~b}), 1.35$ $(1 \mathrm{H}, \mathrm{m}, \mathrm{H}-7 \mathrm{~b}), 1.23,1.21,1.20\left(3 \times \mathrm{OOCCH}\left(\mathrm{CH}_{3}\right)_{2}, \mathrm{~d}\right.$, $\mathrm{J}=6.8 \mathrm{~Hz}), 1.04(3 \mathrm{H}, \mathrm{s}, \mathrm{H}-23), 1.03(1 \mathrm{H}, \mathrm{m}, \mathrm{H}-19 \mathrm{~b})$, $0.98(3 \mathrm{H}, \mathrm{s}, \mathrm{H}-25), 0.96(1 \mathrm{H}, \mathrm{m}, \mathrm{H}-1 \mathrm{~b}), 0.92(3 \mathrm{H}, \mathrm{s}$, $\mathrm{H}-29), 0.91(3 \mathrm{H}, \mathrm{s}, \mathrm{H}-26), 0.90(3 \mathrm{H}, \mathrm{s}, \mathrm{H}-30), 0.82$ ( $3 \mathrm{H}, \mathrm{s}, \mathrm{H}-24), 0.81(1 \mathrm{H}, \mathrm{m}, \mathrm{H} 5),{ }^{13} \mathrm{C}$ NMR $(150 \mathrm{MHz}$ $\left.\mathrm{CDCl}_{3}\right) \delta$ 178.0, 177.7, $176.8(3 \times \mathrm{C}=0), 140.0(\mathrm{C}-13)$, 125.0 (C-12), 80.4 (C-3), 78.4 (C-21), 75.5 (C-22), 69.5 (C-28), 65.2 (C-16), 55.4 (C-5), 46.8 (C-9), 46.7 (C-19), 46.0 (C-17), 41.4 (C-8), 40.1 (C-4), 39.7 $(\mathrm{C}-1), 38.5(\mathrm{C}-14), 37.5(\mathrm{C}-18), 37.0(\mathrm{C}-10), 36.2$ (C$20), 34.8,34.7,34.5,\left(3 \times 00 C \mathrm{CH}\left(\mathrm{CH}_{3}\right)_{2}\right), 33.5\left(\mathrm{C}^{-}\right.$ 15), 32.8 (C-7), 29.0 (C-29), 28.2 (C-27), 28.0 (C23), 24.6 (C-11), 23.6 (C-2), 19.7 (C-30), 19.0, 18.8, $18.7\left(3 \times \mathrm{OOCCH}\left(\mathrm{CH}_{3}\right)_{2}\right), 18.2(\mathrm{C}-6), 17.1(\mathrm{C}-24), 16.9$ (C-26), 16.0 (C-25). ESI-MS (pos. ione mode) at $\mathrm{m} / \mathrm{z}$ $723[\mathrm{M}+\mathrm{Na}]^{+}$. Anal. (Found: $\mathrm{C}, 71.75 ; \mathrm{H}, 9.55$. Calc. For $\left.\mathrm{C}_{42} \mathrm{H}_{68} \mathrm{O}_{8}: \mathrm{C}, 71.96 ; \mathrm{H}, 9.77 \%\right)$.

\section{General Procedures for the Preparation of Compounds $6 a$, b.}

A solution of $1(100.0 \mathrm{mg}, 0.2 \mathrm{mmol})$, pivalic anhydride $(304 \mu \mathrm{l}, 1,5 \mathrm{mmol})$, and DMAP $(12.0 \mathrm{mg}$, $0.099 \mathrm{mmol})$ in dry pyridine $(5 \mathrm{~mL})$ was stirred at $120^{\circ} \mathrm{C}$ for $4 \mathrm{~h}$. The reaction mixture was neutralized with $5 \% \mathrm{HCl}(100 \mathrm{ml})$ and extracted with EtOAc. The organic layer was dried over anhydrous $\mathrm{Na}_{2} \mathrm{SO}_{4}$ and concentrated to dryness under reduced pressure. The residue was chromatographed using a silica gel column with the solvent system Hexane: EtOAc (80:20) to yield $6 \mathrm{a}(35 \mathrm{mg})$ and $6 \mathrm{~b}$ (20 mg).

\section{Olean-12-ene-3,16,21,22,28-pentol, 3,21,22,28-tetra(2,2-dimethylpropanoate) (6a):}

Amorphous white solid; IR $v^{\mathrm{KBr}}{ }_{\max } \mathrm{cm}^{-1}: 3435(>\mathrm{OH})$,
$2950(>\mathrm{CH}), 1735(\mathrm{C}=\mathrm{O}), 1656(\mathrm{C}=\mathrm{C}) ;{ }^{1} \mathrm{H}$ NMR (400 $\left.\mathrm{MHz}, \mathrm{CDCl}_{3}\right) \delta 5.57(1 \mathrm{H}, \mathrm{d}, \mathrm{J}=10.4 \mathrm{~Hz}, \mathrm{H}-21), 5.53$ $(1 \mathrm{H}, \mathrm{d}, \mathrm{J}=10.4 \mathrm{~Hz}, \mathrm{H}-22), 5.34(1 \mathrm{H}, \mathrm{t}, \mathrm{J}=3.5 \mathrm{~Hz}$, $\mathrm{H}-12), 4.44(1 \mathrm{H}, \mathrm{dd}, \mathrm{J}=9.6,6.4 \mathrm{~Hz}, \mathrm{H}-3), 4.06(1 \mathrm{H}$, br s, H-16), $3.72(1 \mathrm{H}, \mathrm{d}, \mathrm{J}=10.8 \mathrm{~Hz}, \mathrm{H}-28 \mathrm{a}), 3.24(1 \mathrm{H}$, $\mathrm{d}, \mathrm{J}=10.8 \mathrm{~Hz}, \mathrm{H}-28 \mathrm{~b}), 2.44(1 \mathrm{H}, \mathrm{m}, \mathrm{H}-19 \mathrm{a}), 2.28(1 \mathrm{H}$, $m, H-18), 1.90(2 \mathrm{H}, \mathrm{m}, \mathrm{H}-11), 1.86(1 \mathrm{H}, \mathrm{m}, \mathrm{H}-2 \mathrm{a}), 1.82$ (1H, m, H-15a), $1.66(1 \mathrm{H}, \mathrm{m}, \mathrm{H}-2 \mathrm{~b}), 1.65(1 \mathrm{H}, \mathrm{m}, \mathrm{H}-9)$, $1.65(1 \mathrm{H}, \mathrm{m}, \mathrm{H}-1 \mathrm{a}), 1.63(1 \mathrm{H}, \mathrm{m}, \mathrm{H}-7 \mathrm{a}), 1.56(1 \mathrm{H}, \mathrm{m}$, $\mathrm{H}-6 \mathrm{a}), 1.44(1 \mathrm{H}, \mathrm{m}, \mathrm{H}-6 \mathrm{~b}), 1.40(3 \mathrm{H}, \mathrm{s}, \mathrm{H}-27), 1.36$ $(1 \mathrm{H}, \mathrm{m}, \mathrm{H}-15 \mathrm{~b}), 1.35$ (1H, m, H-7b) $1.18,1.17,1.16,1.14$ $\left(4 \times 00 C C\left(\mathrm{CH}_{3}\right)_{3}, \mathrm{~s}\right), 1.03(3 \mathrm{H}, \mathrm{s}, \mathrm{H}-23), 1.03(1 \mathrm{H}, \mathrm{m}$, $\mathrm{H}-19 \mathrm{~b}), 0.98(3 \mathrm{H}, \mathrm{s}, \mathrm{H}-25), 0.97(1 \mathrm{H}, \mathrm{m}, \mathrm{H}-1 \mathrm{~b}), 0.93$ $(3 \mathrm{H}, \mathrm{s}, \mathrm{H}-29), 0.91(3 \mathrm{H}, \mathrm{s}, \mathrm{H}-26), 0.90(3 \mathrm{H}, \mathrm{s}, \mathrm{H}-30)$, $0.84(3 \mathrm{H}, \mathrm{s}, \mathrm{H}-24), 0.82(1 \mathrm{H}, \mathrm{m}, \mathrm{H} 5),{ }^{13} \mathrm{C}$ NMR $(150$ $\left.\mathrm{MHz}, \mathrm{CDCl}_{3}\right) \delta 178.4,178.3,178.1,177.1(4 \times \mathrm{C}=0)$, $140.6(C-13), 124.7$ (C-12), 80.4 (C-3), $78.1(C-21), 71.4$ (C-22), 69.7 (C-28), 64.0 (C-16), 55.4 (C-5), 46.9 (C9), 46.7 (C-19), 46.5 (C-17), 41.2 (C-8), 40.0 (C-4), $39.9(\mathrm{C}-1), 39.4,39.3,39.2,39.1\left(4 \times \mathrm{OOCC}\left(\mathrm{CH}_{3}\right)_{3}\right)$, $38.5(\mathrm{C}-14), 38.1(\mathrm{C}-18), 37.1(\mathrm{C}-10), 36.4(\mathrm{C}-20)$, 34.2 (C-15), 32.9 (C-7), 29.1 (C-29), $28.4(\mathrm{C}-27)$, $28.3(\mathrm{C}-23), 27.7,27.6,27.6,27.5\left(4 \times \mathrm{OOCC}\left(\mathrm{CH}_{3}\right)_{3}\right)$, 24.8 (C-11), 23.8 (C-2), 19.7 (C-30), 18.4 (C-6), 17.0 (C-24), 17.0 (C-26), 15.6 (C-25). ESI-MS (pos. ione mode) $\mathrm{m} / \mathrm{z} 849[\mathrm{M}+\mathrm{Na}]^{+}, \mathrm{MS} / \mathrm{MS} \mathrm{m} / \mathrm{z}$ z $747[\mathrm{M}+\mathrm{Na}-$ $\left(\mathrm{CH}_{3) 3} \mathrm{CCOOH}\right]^{+}, 645\left[\mathrm{M}+\mathrm{Na}-2\left(\left(\mathrm{CH}_{3) 3} \mathrm{CCOOH}\right)\right]^{+}\right.$, $543 \quad\left[\mathrm{M}+\mathrm{Na}-3\left(\left(\mathrm{CH}_{3) 3} \mathrm{CCOOH}\right)\right]^{+}, \quad 441\right.$ $\left[\mathrm{M}+\mathrm{Na}-4\left(\left(\mathrm{CH}_{3) 3} \mathrm{CCOOH}\right)\right]^{+}\right.$. Anal. (Found: $\mathrm{C}, 72.80$; $\mathrm{H}$, 10.01. Calc. For $\left.\mathrm{C}_{50} \mathrm{H}_{82} \mathrm{O}_{9}: \mathrm{C}, 72.60 ; \mathrm{H}, 9.99 \%\right)$.

\section{Olean-12-ene-3,16,21,22,28-pentol,} 3,21,28-tris(2,2-dimethylpropanoate) (6b):

Amorphous white solid; IR $v^{\mathrm{KBr}}{ }_{\max } \mathrm{cm}^{-1}: 3430(>\mathrm{OH})$, $2948(>\mathrm{CH}), 1734(\mathrm{C}=\mathrm{O}), 1656(\mathrm{C}=\mathrm{C}) ;{ }^{1} \mathrm{H}$ NMR (400 $\left.\mathrm{MHz}, \mathrm{CDCl}_{3}\right) \delta 5.38(1 \mathrm{H}, \mathrm{d}, \mathrm{J}=10.0 \mathrm{~Hz}, \mathrm{H}-21), 5.34$ $(1 \mathrm{H}, \mathrm{t}, \mathrm{J}=3.5 \mathrm{~Hz}, \mathrm{H}-12), 4.46(1 \mathrm{H}, \mathrm{dd}, \mathrm{J}=9.6,6.4 \mathrm{~Hz}$, $\mathrm{H}-3), 4.23(1 \mathrm{H}, \mathrm{br} \mathrm{s}, \mathrm{H}-16), 3.86(1 \mathrm{H}, \mathrm{d}, \mathrm{J}=10.0 \mathrm{~Hz}$, $\mathrm{H}-22), 3.86(1 \mathrm{H}, \mathrm{d}, \mathrm{J}=11.2 \mathrm{~Hz}, \mathrm{H}-28 \mathrm{a}), 3.77(1 \mathrm{H}, \mathrm{d}$, $\mathrm{J}=11.2 \mathrm{~Hz}, \mathrm{H}-28 \mathrm{~b}), 2.45(1 \mathrm{H}, \mathrm{m}, \mathrm{H}-19 \mathrm{a}), 2.27(1 \mathrm{H}, \mathrm{m}$, $\mathrm{H}-18), 1.90(2 \mathrm{H}, \mathrm{m}, \mathrm{H}-11), 1.85(1 \mathrm{H}, \mathrm{m}, \mathrm{H}-2 \mathrm{a}), 1.82$ $(1 \mathrm{H}, \mathrm{m}, \mathrm{H}-15 \mathrm{a}), 1.65(1 \mathrm{H}, \mathrm{m}, \mathrm{H}-2 \mathrm{~b}), 1.64(1 \mathrm{H}, \mathrm{m}, \mathrm{H}-9)$, $1.64(1 \mathrm{H}, \mathrm{m}, \mathrm{H}-1 \mathrm{a}), 1.63(1 \mathrm{H}, \mathrm{m}, \mathrm{H}-7 \mathrm{a}), 1.56(1 \mathrm{H}, \mathrm{m}$, $\mathrm{H}-6 \mathrm{a}), 1.45(1 \mathrm{H}, \mathrm{m}, \mathrm{H}-6 \mathrm{~b}), 1.41(3 \mathrm{H}, \mathrm{s}, \mathrm{H}-27), 1.37$ $(1 \mathrm{H}, \mathrm{m}, \mathrm{H}-15 \mathrm{~b}), 1.35(1 \mathrm{H}, \mathrm{m}, \mathrm{H}-7 \mathrm{~b}), 1.22,1.21,1.20$ $\left(3 \times \mathrm{OOCC}\left(\mathrm{CH}_{3}\right)_{3}, \mathrm{~s}\right), 1.03(3 \mathrm{H}, \mathrm{s}, \mathrm{H}-23), 1.02(1 \mathrm{H}, \mathrm{m}$, $\mathrm{H}-19 \mathrm{~b}), 0.98(3 \mathrm{H}, \mathrm{s}, \mathrm{H}-25), 0.97(1 \mathrm{H}, \mathrm{m}, \mathrm{H}-1 \mathrm{~b}), 0.93$ $(3 \mathrm{H}, \mathrm{s}, \mathrm{H}-29), 0.91(3 \mathrm{H}, \mathrm{s}, \mathrm{H}-26), 0.90(3 \mathrm{H}, \mathrm{s}, \mathrm{H}-30)$, $0.83(3 \mathrm{H}, \mathrm{s}, \mathrm{H}-24), 0.82(1 \mathrm{H}, \mathrm{m}, \mathrm{H} 5),{ }^{13} \mathrm{C}$ NMR $(150$ $\left.\mathrm{MHz}_{1} \mathrm{CDCl}_{3}\right) \delta 179.8,178.1,178.1(3 \times \mathrm{C}=0), 140.6$ 
(C-13), 124.6 (C-12), 80.9 (C-21), 80.1 (C-3), 72.9 (C22), 68.3 (C-28), 66.2 (C-16), 55.4 (C-5), 46.8 (C9), 46.7 (C-19), 46.4 (C-17), 41.2 (C-8), 40.1 (C-4), $39.9(\mathrm{C}-1), 39.4,39.3,39.2\left(3 \times \mathrm{OOCC}\left(\mathrm{CH}_{3}\right)_{3}\right), 38.4$ (C-14), 38.1 (C-18), 37.0 (C-10), $36.4(\mathrm{C}-20), 34.1$ (C-15), 32.9 (C-7), 29.0 (C-29), $28.4(\mathrm{C}-27), 28.2$ $(\mathrm{C}-23), 27.7,27.6,27.6\left(4 \times \mathrm{OOCC}\left(\mathrm{CH}_{3}\right)_{3}\right), 24.7(\mathrm{C}-$ 11), 23.8 (C-2), 19.6 (C-30), 18.4 (C-6), 17.1 (C-24), 17.0 (C-26), 15.7 (C-25). ESI-MS (pos. ione mode) $\mathrm{m} / \mathrm{z} 765[\mathrm{M}+\mathrm{Na}]^{+}, \mathrm{MS} / \mathrm{MS} \mathrm{m} / \mathrm{z}$ z $663[\mathrm{M}+\mathrm{Na}-$ $\left(\mathrm{CH}_{333} \mathrm{CCOOH}\right]^{+}, 561\left[\mathrm{M}+\mathrm{Na}-2\left(\left(\mathrm{CH}_{333} \mathrm{CCOOH}\right)\right]^{+}, 459\right.$ $\left[\mathrm{M}+\mathrm{Na}-3\left(\left(\mathrm{CH}_{3) 3} \mathrm{CCOOH}\right)\right]^{+}\right.$. Anal. (Found: $\mathrm{C}, 72.60$; $\mathrm{H}, 10.10$. Calc. For $\left.\mathrm{C}_{45} \mathrm{H}_{74} \mathrm{O}_{8}: \mathrm{C}, 72.74 ; \mathrm{H}, 10.04 \%\right)$.

\section{Olean-12-ene-3,16,21,22,28-pentol, 3,21,22,28-tetrabenzoate (7):}

A solution of $1(100.0 \mathrm{mg}, 0.2 \mathrm{mmol})$, benzoic anhydride (339 mg, 1,5 mmol), and DMAP (12.0 $\mathrm{mg}, 0.099 \mathrm{mmol})$ in dry pyridine $(5 \mathrm{~mL})$ was stirred at $120^{\circ} \mathrm{C}$ for $4 \mathrm{~h}$. The reaction mixture was neutralized with $5 \% \mathrm{HCl}(100 \mathrm{ml})$ and extracted with EtOAc. The organic layer was dried over anhydrous $\mathrm{Na}_{2} \mathrm{SO}_{4}$ and concentrated to dryness under reduced pressure. The residue was chromatographed using a silica gel column with the solvent system Hexane: EtOAc (80:20) to yield 7 (35mg). Amorphous white solid; IR $\mathrm{n}^{\mathrm{KBr}}{ }_{\max } \mathrm{cm}^{-1}$ : $3433(>\mathrm{OH}), 2945(>\mathrm{CH}), 1716(\mathrm{C}=0), 1655(\mathrm{C}=\mathrm{C})$; ${ }^{1} \mathrm{H}$ NMR $\left(400 \mathrm{MHz}, \mathrm{CDCl}_{3}\right) \delta 8.06,7.86,7.86,7.76$ $\left(4 \times \mathrm{H}-2^{\prime}, 6^{\prime}\right), 7.30,7.27,7.27,7.25\left(4 \times \mathrm{H}^{\prime} 3^{\prime}, 5^{\prime}\right), 7.45$, 7.44, 7.44, $7.43\left(4 \times \mathrm{H}^{\prime} 4^{\prime}\right), 6.10(1 \mathrm{H}, \mathrm{d}, \mathrm{J}=10.4 \mathrm{~Hz}$, $\mathrm{H}-21), 6.00(1 \mathrm{H}, \mathrm{d}, \mathrm{J}=10.4 \mathrm{~Hz}, \mathrm{H}-22), 5.33(1 \mathrm{H}, \mathrm{t}$, $\mathrm{J}=3.5 \mathrm{~Hz}, \mathrm{H}-12), 4.75(1 \mathrm{H}, \mathrm{dd}, \mathrm{J}=9.5,6.5 \mathrm{~Hz}, \mathrm{H}-3)$, $4.54(1 \mathrm{H}, \mathrm{br} \mathrm{s}, \mathrm{H}-16), 4.19(1 \mathrm{H}, \mathrm{d}, \mathrm{J}=11.2 \mathrm{~Hz}, \mathrm{H}-28 \mathrm{a})$, $4.01(1 \mathrm{H}, \mathrm{d}, \mathrm{J}=11.2 \mathrm{~Hz}, \mathrm{H}-28 \mathrm{~b}), 2.45(1 \mathrm{H}, \mathrm{m}, \mathrm{H}-19 \mathrm{a})$, $2.27(1 \mathrm{H}, \mathrm{m}, \mathrm{H}-18), 1.91(2 \mathrm{H}, \mathrm{m}, \mathrm{H}-11), 1.86(1 \mathrm{H}, \mathrm{m}$, $\mathrm{H}-2 \mathrm{a}), 1.83(1 \mathrm{H}, \mathrm{m}, \mathrm{H}-15 \mathrm{a}), 1.66(1 \mathrm{H}, \mathrm{m}, \mathrm{H}-2 \mathrm{~b}), 1.65$ $(1 \mathrm{H}, \mathrm{m}, \mathrm{H}-9), 1.65(1 \mathrm{H}, \mathrm{m}, \mathrm{H}-1 \mathrm{a}), 1.62(1 \mathrm{H}, \mathrm{m}, \mathrm{H}-7 \mathrm{a})$, $1.56(1 \mathrm{H}, \mathrm{m}, \mathrm{H}-6 \mathrm{a}), 1.44(1 \mathrm{H}, \mathrm{m}, \mathrm{H}-6 \mathrm{~b}), 1.40(3 \mathrm{H}, \mathrm{s}$, $\mathrm{H}-27), 1.37(1 \mathrm{H}, \mathrm{m}, \mathrm{H}-15 \mathrm{~b}), 1.35(1 \mathrm{H}, \mathrm{m}, \mathrm{H}-7 \mathrm{~b}), 1.03$ $(3 \mathrm{H}, \mathrm{s}, \mathrm{H}-23), 1.02(1 \mathrm{H}, \mathrm{m}, \mathrm{H}-19 \mathrm{~b}), 0.99(3 \mathrm{H}, \mathrm{s}, \mathrm{H}-25)$, $0.98(1 \mathrm{H}, \mathrm{m}, \mathrm{H}-1 \mathrm{~b}), 0.92(3 \mathrm{H}, \mathrm{s}, \mathrm{H}-29), 0.91(3 \mathrm{H}$, $\mathrm{s}, \mathrm{H}-26), 0.90(3 \mathrm{H}, \mathrm{s}, \mathrm{H}-30), 0.85(3 \mathrm{H}, \mathrm{s}, \mathrm{H}-24)$, $0.82(1 \mathrm{H}, \mathrm{m}, \mathrm{H} 5),{ }^{13} \mathrm{C} \mathrm{NMR}\left(150 \mathrm{MHz}, \mathrm{CDCl}_{3}\right) \delta 175.1$, 174.3, 174.1, $173.7(4 \times \mathrm{C}=0), 140.6(\mathrm{C}-13), 130.4$, 129.8, $129.7129 .7(4 \times C-4 '), 128.6,128.6,128.5$, $128.5\left(4 \times C^{\prime} 1^{\prime}\right), 128.3,128.3,128.2,128.2(4 \times C-$ $\left.2^{\prime}, 6^{\prime}\right), 128.1,128.1,128.0,128.0\left(4 \times C-3^{\prime}, 5^{\prime}\right), 124.8$ (C-12), 81.4 (C-3), 78.8 (C-21), 72.1 (C-22), 68.1 (C28), 64.7 (C-16), 55.4 (C-5), 46.9 (C-9), 46.7 (C-19),
46.4 (C-17), 41.2 (C-8), 40.0 (C-4), 39.9 (C-1), 38.5 (C-14), 38.1 (C-18), 37.0 (C-10), 36.4 (C-20), 34.2 (C15), 32.8 (C-7), 29.1 (C-29), 28.5 (C-27), 28.3 (C-23), 24.9 (C-11), 23.9 (C-2), 19.8 (C-30), 18.5 (C-6), 17.3 (C-24), 17.0 (C-26), 15.8 (C-25). ESI-MS (pos. ione mode) $\mathrm{m} / \mathrm{z} 929[\mathrm{M}+\mathrm{Na}]^{+}, \mathrm{MS} / \mathrm{MS} \mathrm{m} / \mathrm{z} 807[\mathrm{M}+\mathrm{Na}-$ $\left.\mathrm{C}_{6} \mathrm{H}_{5} \mathrm{COOH}\right]^{+}, \quad 685 \quad\left[\mathrm{M}+\mathrm{Na}-2\left(\mathrm{C}_{6} \mathrm{H}_{5} \mathrm{COOH}\right)\right]^{+}, 563$ $\left[\mathrm{M}+\mathrm{Na}-3\left(\mathrm{C}_{6} \mathrm{H}_{5} \mathrm{COOH}\right)\right]^{+}, 441\left[\mathrm{M}+\mathrm{Na}-4\left(\mathrm{C}_{6} \mathrm{H}_{5} \mathrm{COOH}\right)\right]^{+}$. Anal. (Found: $\mathrm{C}, 76.51 ; \mathrm{H}, 7.35$. Calc. For $\mathrm{C}_{58} \mathrm{H}_{66} \mathrm{O}_{9}$ : C, $76.79 ; \mathrm{H}, 7.33 \%)$.

\section{Cell Culture and in vitro Cytotoxicity Assay}

Human lung adenocarcinoma epithelial (A549), human cervix adenocarcinoma (HeLa), human colorectal adenocarcinoma ( $\mathrm{CaCo}-2)$, human glioblastoma-astrocytoma (U-87 MG), human breast adenocarcinoma (MCF-7) cells were used as cancer cell lines. Kidney epithelial cells from an African green monkey (Vero) were used as a noncancerous cell line. Cell lines were purchased from Deutsche Sammlung von Mikroorganismen und Zellkulturen (DSMZ, Germany). All the cells were maintained in Dulbecco's modified Eagle's medium (DMEM), supplemented with $10 \%$ fetal bovine serum (FBS), $2 \mathrm{mM}$ L-glutamine, $100 \mathrm{U} / \mathrm{mL}$ of penicillin and $100 \mu \mathrm{g} / \mathrm{mL}$ of streptomycin (Biochrom $A G$, Berlin, Germany). The cells were incubated at $37^{\circ} \mathrm{C}$ in a humidified atmosphere of $5 \% \mathrm{CO}_{2}$.

Cytotoxicity of compounds were determined by following the general procedure based on cell viability using a modified MTT [3-(4, 5- Dimethyl2-thiazolyl)-2, 5-diphenyl-2H-tetrazolium bromide)] $[53,54]$ which measures the activity of mitochondrial reductase of viable cells colorimetrically. The assay is based on cleavage of MTT that forms formazan crystals. This cleavage appears in living cells with succinate-dehydrogenase. Adding dimethyl sulfoxide to wells helps formazan crystals to be dissolved. The optical density (OD) was measured at $570 \mathrm{~nm}$ (with a reference at $690 \mathrm{~nm}$ ) by U.V. visible spectrophotometer (Thermo Scientific, USA) in triplicates. All cell lines were cultivated for $24 \mathrm{~h}$ in 96-well microplates with an initial concentration of $1 \times 10^{5}$ cells $/ \mathrm{ml}$. Then, the cultured cells were treated with different doses of 0-100 $\mu \mathrm{M}$ and incubated for $48 \mathrm{~h}$ at $37^{\circ} \mathrm{C}$. Doxorubicin, a chemotherapeutic agent, was used as a positive cytotoxic control drug. Percentages of surviving cells in each culture were determined after treat- 
ment of venom. The \% viability was determined as formulated below:

Viable cells $(\%)=[($ The absorbance of the treated cells) (the absorbance of the blank)]/[(The absorbance of the control)-(the absorbance of the blank)] $\times 100$

\section{Determination of $\mathrm{IC}_{50}$}

Inhibition of growth $50 \%\left(\mathrm{IC}_{50}\right)$, which is the concentration of compounds causing $50 \%$ inhibition in cell growth compared to untreated controls, calculated by using OD values of controls and compounds doses as described previously. Cytotoxicity was expressed as an increase of the mean percentage of cytotoxicity relative to the unexposed control \pm standard deviation (SD). Control values were set at $0 \%$ cytotoxicity. $I_{50}$ was calculated by fitting the data to a sigmoidal curve and using a four parameters logistic model and presented as an average of three independent measurements. The $I C_{50}$ values were reported at $95 \%$ confidence interval and calculation was performed using GraphPad Prism software (San Diego, USA). The values of the blank wells were subtracted from each well of treated and control cells and inhibition of growth $50 \%$ was calculated in comparison with untreated controls.

\section{CONCLUSIONS}

In conclusion, 16 ester derivatives of barringtogenol C (1) have been synthesized and evaluated for the growth inhibition of various cancer cells such as CaCo-2, HeLa, MCF-7, A549 and U87MG cancer cell lines together with normal cells Vero. Several compounds have been found to have better or comparable anti-cancer potency in comparison with doxorubicin or barringtogenol C (1). Moreover, the cytotoxicity of the synthesized compounds appears to be selective on non-tumoral Vero cells, which tolerated substantially higher doses of these compounds than tumor cells. Among these, compounds $\mathbf{2} \mathbf{a}, \mathbf{2} \mathbf{b}$ bearing an isopropylidene group at C21, C22 and C21, C28 showed an enhanced cytotoxic activity against the U87MG and $\mathrm{CaCo}-2$ cell lines, respectively. However, the addition of isopropylidene moiety at C21, C22, C16 and $\mathrm{C} 28,(\mathbf{2 b})$ increased the activity of $\mathbf{1}$ on MCF-7, A549 and U87MG cell lines. While esterification of hydroxyl groups at C3, C21, C22 and C28 positions with propiyonic acid (3a) produced a considerable increase in the activity of 1 on U87MG cell lines, the addition of propanoate moiety at C3, C21 and C28 (3b) or C3, C22 and C28 (3c) positions led to an increase in cytotoxicity of U87MG and A549 cell lines. Regarding compound $\mathbf{4 c}$, the results showed that substitution of C3, C22 and C28 hydroxyl groups with butanoic acid moiety increased activity against to U87MG and A549 cell lines. In case of compound $\mathbf{5 d}$, isobutanoate groups at C3, C22 and C28 positions increased cytotoxicity against to U87MG cell lines. Nevertheless, the addition of benzoate moiety at C3, C21 and C28 positions (7) resulted in increased activity of 1 on U87MG cell lines.

\section{ACKNOWLEDGEMENTS}

We would also like to extend our thanks to AREL and AREL staff for their support since we used the laboratory facilities of AREL (Research and Education Laboratory, Ege University School of Medicine, Bornova Izmir Turkey) during the study.

\section{References}

1. M. Recio, C. Del, R.M. Giner, Structural requirements for the anti-inflammatory activity of natural triterpenoids, Planta Med., 61 (1995) 182-185.

2. E.K.Yim, M.J.Lee, K.H.Um, J.S. Park, Antiproliferative and antiviral mechanisms of ursolic acid and dexamethasone in cervical carcinoma cell lines, Int. Cynecol. Cancer, 16 (2006) 2023-2031.

3. D.K. Kim, J.H. Baek, C.M. Kang, M.A. Yoo, J.W. Sung, D. Kim,. H.Y. Chung, N.D. Kim, Y.H. Choi, S.H. Lee, K. Kim, Apoptotic activity of ursolic acid may correlate with the inhibition of initiation of DNA replication, Int. J. Cancer, 87 (2000) 629-636.

4. P.O. Harmand, R. Duval, C. Delage, A. Simon, Ursolic acid induces apoptosis through mitochondrial intrinsic pathway and caspase-3 activation in M4Beu melanoma cells, Int. J. Cancer, 114 (2005) 1-11.

5. J.J. Liu, Pharmacology of oleanolic acid and ursolic acid, Ethnopharmacol., 49 (1995) 57-68.

6. P. Dzubak, M. Hajduch, D. Vydra, A. Hustova, M. Kvasnica, D. Biedermann, L. Markova, M. Urban, J. Sarek, Pharmacological activities of natural triterpenoids and their therapeutic implications, Nat. Prod. Rep., 23 (2006) 394-411.

7. A. Esmaillzadeh, F. Tahbaz, I. Gaieni, H. Alavi-Majd, L. Azadbakht, Concentrated pomegranate juice improves lipid profiles in diabetic patients with hyperlipidemia, J. Med. Food, 7 (2004) 305-308.

8. W.S. Lee, K.R. Im, Y.D. Park, N.D. Sung, T.S. Jeong, Human ACAT-1 and ACAT-2 inhibitory activities of pentacyclic triterpenes from the leaves of Lycopus lucidus TURCZ, Biol. Pharm. Bull., 29 (2006) 382-384. 
9. J.H. Lee, Y.B. Ryu, B.W. Lee, J.H. Kim, W.S. Lee, Y.D. Park, T.S. Jeong, K.H. Park, Human Acyl-CoA: cholesterol acyltransferase (hACAT) inhibitory activities of triterpenoids from roots of glycine max (L.) Merr., Bull. Korean Chem. Soc., 29 (2008) 615-619.

10. J.M. Narvaez-Mastache, M.L. Garduno-Ramirez, L. Alvarez, G. Delgado, Antihyperglycemic activity and chemical constituents of Eysenhardtia platycarpa, J. Nat. Prod., 69 (2006) 1687-1691.

11. D. Gao, Q. Li, Y. Li, Z. Liu, Z. Liu, Y. Fan, Z. Han, J. Li, K. Li, Antidiabetic potential of oleanolic acid from Ligustrum lucidum Ait., Can. J. Physiol. Pharmacol., 85 (2007) 1076-1083.

12. P. Kalaiarasi, K.V. Pugalendi, Antihyperglycemic effect of 18 beta-glycyrrhetinic acid, aglycone of glycyrrhizin, on streptozotocin-diabetic rats, Eur. J. Pharmacol., 606 (2009) 269.

13. L.I. Somova, F.O. Shode, P. Ramnanan, A. Nadar, Antihypertensive, antiatherosclerotic and antioxidant activity of triterpenoids isolated from Olea europaea subspecies africana leaves. J. Ethnopharmacol., 84 (2003) 299-305..

14. L. Saaby, A.K. Jäger, L. Moesby, E.W. Hansen, S.B. Christensen, Isolation of immunomodulatory triterpene acids from a standardized rose hip powder (Rosa canina L.), Phytother. Res., 25 (2011) 195-201.

15. R. Martin, J.C. Tavares, M. Hernandez, M. Arne's, V.R. Gutierrez, M.L. Nieto, Beneficial actions of oleanolic acid in an experimental model of multiple sclerosis: a potential therapeutic role, Biochem. Pharmacol., 79 (2010) 198-208.

16. U. Weissenstein, U.D. Toffol-Schmidt, S. Baumgartner, K. Urech, Effect of Viscum album lipohilic extract on human immunocompetent cells in vitro, Phytomedicine, 18 (2011) 18-23.

17. J. Lu, Y.L. Zheng, D.M. Wu, L. Luo, D.X. Sun, Q. Shan, Ursolic acid ameliorates cognition deficits and attenuates oxidative damage in the brain of senescent mice induced by D-galactose, Biochem. Pharmacol. 74 (2007) 1078-1090.

18. L. Li, X. Zhang, L. Cui, L. Wang, H. Liu, H. Ji, Y. Du, Ursolic acid promotes the neuroprotection by activating Nrf2 pathway after cerebral ischemia in mice, Brain Res., 1497 (2013) 32-39.

19. K.T. Liby, M.M. Yore, M.B. Sporn, Triterpenoids and rexinoids as multifunctional agents for the prevention and treatment of cancer, Nat. Rev. Cancer, 7 (2007) 357-369.

20. A. Bishayee, S. Ahmed, N. Brankov, M. Perloff, Triterpenoids as potential agents for the chemo prevention and therapy of breast cancer, Front. Biosci., 16 (2011) 980-996.

21. R. Csuk, R. Sczepek, B. Siewert, C. Nitsche, Cytotoxic betulin-derived hydroxypropargylamines trigger apoptosis, Bioorgan. Med. Chem., 21 (2013) 425-435.

22. S. Shishodia, S. Majumdar, S. Banerjee, B.B. Aggarwal, Ursolic acid inhibits nuclear factor-kappaB activation induced by carcinogenic agents through suppression of IkappaBalpha kinase and p65 phosphorylation: correlation with down-regulation of cyclooxygenase 2, matrix metalloproteinase 9, and cyclin D1, Cancer Res., 63 (2003) 4375-4383.

23. H.R. Metelmann, J. Brandner, H. Schumann, F. Bross, M. Hoffmann, F. Podmelle, Accelerating the aesthetic benefit of wound healing by triterpene, J. CranioMaxill. Surg., 40 (2012) 150-154.
24. R. Kuonen, P. Heusser, U. Weissenstein, S. Baumgartner, K. Urech, M. Kunz, K. Hostanska, M. Estko, Effects of lipophilic extract of Viscum album L. and oleanolic acid on migratory activity of NIH/3T3 fibroblasts and on $\mathrm{HaCat}$ keratinocytes, Evid. Based Compl. Alt., 3 (2013) 1-8.

25. I. Baglin, A.C. Mitaine-Offer, M. Nour, C.C. Tan, M.A. Lacaille-Dubois, A review of natural and modified betulinic, ursolic and echinocystic acid derivatives as potential antitumor and anti-HIV agents, Mini-Rev. Med. Chem., 3 (2003) 525-539.

26. K.T. Liby, M.M. Yore, M.B. Sporn, Triterpenoids and rexinoids as multifunctional agents for the prevention and treatment of cancer, Nat. Rev. Cancer, 7 (2007) 357-369.

27. F.B. Mullauer, J.H. Kessler, J.P. Medema, Betulinic acid, a natural compound with potent anticancer effects, Anti-Cancer Drug, 21 (2010) 215-227.

28. Q. Zhang, Z. Chang, Q. Wang, Ursane triterpenoids inhibit atherosclerosis and xanthoma in LDL receptor knockout mice, Cardiovasc. Drugs Ther., 20 (2006) 349-357.

29. H. Assefa, A. Nimrod, L. Walker, R. Sindelar, Synthesis and evaluation of potential complement inhibitory semisynthetic analogs of oleanolic acid, Bioorg. Med. Chem. Lett., 9 (1999) 1889.

30. Y.Q. Meng, D. Liu, L.L. Cai, H. Chen, B. Cao, Y.Z. Wang, The synthesis of ursolic acid derivatives with cytotoxic activity and the investigation of their preliminary mechanism of action, Bioorgan. Med. Chem., 17 (2009) 848-854.

31. H.J. Jeong, H.B. Chai, S.Y. Park, D.S. Kim, Preparation of amino acid conjugates of betulinic acid with activity against human melanoma, Bioorg. Med. Chem. Lett., 9 (1999) 1201-1204.

32. W.K. Liu, J.C. Ho, F.W. Cheung, B.P. Liu, W.C. Ye, C.T. Che, Apoptotic activity of betulinic acid derivatives on murine melanoma B16 cell line, Eur. J. Pharmacol., 498 (2004) 71-78.

33. M. Lu, L. Xia, H. Hua, Y. Jing, Acetyl-keto- $\beta$ boswellic acid induces apoptosis through a death receptor 5-mediated pathway in prostate cancer cells, Cancer Res., 7 (2008) 1180-1186.

34. V.R. Yadav, S. Prasad, B. Sung, J.G. Gelovani, S. Guha, S. Krishnan, B.B. Aggarwal, Boswellic acid inhibits growth and metastasis of human colorectal cancer in orthotopic mouse model by downregulating inflammatory, proliferative, invasive and angiogenic biomarkers, Int J. Cancer, 7 (2011) 2176-2184.

35. J.A.R. Salvador, V.M. Moreira, B.M.F. Gonçalves, A.S. Leal, Y. Jing, Ursane-type pentacyclic triterpenoids as useful platforms to discover anticancer drugs, Nat. Prod. Rep., 29 (2012) 1463-1479.

36. H.X. Sun, Q.F. Zheng, J. Tu, Induction of apoptosis in HeLa cells by 3beta-hydroxy-12-oleanen-27-oic acid from the rhizomes of Astilbe chinensis, Bioorg. Med. Chem., 14 (2006) 1189-1198.

37. Y. Ito, P. Pandey, A. Place, M.B. Sporn, G.W. Gribble, T. Honda, S. Kharbanda, D. Kufe, The novel triterpenoid 2-cyano-3,12-dioxoolean-1,9dien-28-oic acid induces apoptosis of human myeloid leukemia cells by a caspase-8-dependent mechanism, Cell Growth Differ., 11 (2000) 261-267. 
38. I.M. Pedersen, S. Kitada, A. Schimmer, Y. Kim, J.M Zapata, L. Charboneau, L. Rassenti, M. Andreeff F. Bennett, M.B. Sporn, L.D. Liotta, T.J. Kipps, J.C. Reed, The triterpenoid CDDO induces apoptosis in refractory CLL B cells, Blood 100 (2002) 2965-2972.

39. Y. Ito, P. Pandey, M.B. Sporn, R. Datta, S Kharbanda, D. Kufe, The novel triterpenoid CDDO induces apoptosis and differentiation of human osteosarcoma cells by a caspase- 8 dependent mechanism, Mol. Pharmacol., 59 (2001) 1094-1099.

40. H. Lapillonne, M. Konopleva, T. Tsao, D. Gold, T. McQueen, R.L. Sutherland, T. Madden, M. Andreeff Activation of peroxisome proliferator-activated receptor gamma by a novel synthetic triterpenoid 2-cyano-3,12-dioxooleana-1,9-dien-28-oic acid induces growth arrest and apoptosis in breast cancer cells, Cancer Res., 63 (2003) 5926-5939.

41. X. Gao, D. Deeb, H. Jiang, Y. Liu, S. A. Dulchavsky, S. C. Gautam, Synthetic triterpenoids inhibit growth and induce apoptosis in human glioblastoma and neuroblastoma cells through inhibition of prosurvival Akt, NF-kappaB and Notch1 signaling, J Neurooncol., 84 (2007) 147-157.

42. G. Speranza, R.J. Parker, J.H. Doroshow, M.E. Gutierrez, J. Collins, A. Chen, Phase I study of the synthetic triterpenoid, 2-cyano-3, 12-dioxoolean-1, 9-dien-28-oic acid (CDDO), in advanced solid tumors, Cancer Chemother. Pharmacol., 69 (2012) 431-438.

43. P.M. Gowri, S.V.S. Radhakrishnan, S.J. Basha, A.V.S. Sarma, J.M. Rao, Oleanane-type isomeric triterpenoids from Barringtonia racemosa, J. Nat. Prod., 72 (2009) 791-795.

44. V. Lanzotti, P. Termolino, M. Dolci, P. Curir Paviosides $\mathrm{A}-\mathrm{H}$, eight new oleane type saponins from Aesculus pavia with cytotoxic activity, Bioorgan. Med. Chem., 20 (2012) 3280-3286.

45. P. Wang, W. Yuan, G. Deng, Z. Su, S. Li, Triterpenoid saponins from Eryngium yuccifolium 'Kershaw Blue', Phytochem. Lett., 6 (2013) 306-309.
46. D. Mandal, N. Panda, S. Kumar, S. Banerjee, N.B. Mandal, N.P. Sahu, A triterpenoid saponin possessing antileishmanial activity from the leaves of Careya arborea, Phytochemistry, 67 (2006) 183190.

47. K. Yoshikawa, H. Hirai, M. Tanaka, S. Arihara, Antisweet natural products. XV. Structures of Jegosaponins A-D from Styrax japonica Sieb. et Zucc., Chem. Pharm. Bull., 48 (2000) 1093-1096.

48. H. Anil, 21-benzoyl-barringtogenol C, A Sapogenin from Styrax officinalis, Phytochemistry, 18 (1979) 1760-1761.

49. Y. Yayla, O.A. Caliskan, H. Anıl, R.B. Bates, C.C. Stessman, V.V. Kane, Saponin from Styrax officinalis, Fitoterapia, 73 (2002) 320-326.

50. M. Yoshikawa, T. Murakami, H. Matsuda, J. Yamahara, N. Murakami, I. Kitagawa, Bioactive saponins and glycosides. III. Horse chestnut. (1): The structures, inhibitory effects on ethanol absorption, and hypoglycemic activity of escins Ia, Ib, IIa, IIb, and IIla from the seeds of Aesculus hippocastanum L., Chem. Pharm. Bull., 44 (1996) $1454-1464$

51. A.A. Magid, H. Bobichon, N. Borie, N. Lalun, C. Long, C. Moretti, C. Lavaud, Cytotoxic triterpenoid saponins from the stem bark of Antonia ovata, Phytochemistry, 71 (2010) 429-434.

52. P. Wang, S. Ownby, Z. Zhang, W. Yuan, S. Li, Cytotoxicity and inhibition of DNA topoisomerase I of polyhydroxylated triterpenoids and triterpenoid glycosides, Bioorgan. Med. Chem. Lett., 20 (2010) 2790-2796.

53. T. Mosmann, Rapid colorimetric assay for cellular growth and survival: application to proliferation and cytotoxicity assays, J. Immunol. Methods, 65 (1983) 55-63.

54. M. Urgen, F. Kocabaş, A. Nalbantsoy, E. Hameş Kocabas, A. Uzel, E. Bedir, Bioassay-guided isolation studies on Mesophilic Actinomycete M-335 possessing antibacterial and cytotoxic activities, Nat. Prod. Comm., 5 (2010) 249-252. 